Pacific Northwest

National Laboratory

Operated by Battelle for the

U.S. Department of Energy

\title{
Vessel-Spanning Bubble Formation in K-Basin Sludge Stored in Large-Diameter Containers
}

\author{
G. Terrones
}

P.A. Gauglitz

March 2002

Prepared for the U.S. Department of Energy under Contract DE-AC06-76RL01830 


\title{
DISCLAIMER
}

This report was prepared as an account of work sponsored by an agency of the United States Government. Neither the United States Government nor any agency thereof, nor Battelle Memorial Institute, nor any of their employees, makes any warranty, express or implied, or assumes any legal liability or responsibility for the accuracy, completeness, or usefulness of any information, apparatus, product, or process disclosed, or represents that its use would not infringe privately owned rights. Reference herein to any specific commercial product, process, or service by trade name, trademark, manufacturer, or otherwise does not necessarily constitute or imply its endorsement, recommendation, or favoring by the United States Government or any agency thereof, or Battelle Memorial Institute. The views and opinions of authors expressed herein do not necessarily state or reflect those of the United States Government or any agency thereof.

\author{
PACIFIC NORTHWEST NATIONAL LABORATORY \\ operated by \\ BATTELLE \\ for the \\ UNITED STATES DEPARTMENT OF ENERGY \\ under Contract DE-AC06-76RL01830
}

This document was printed on recycled paper 


\section{Vessel-Spanning Bubble Formation in K-Basin Sludge Stored in Large-Diameter Containers}

G. Terrones

P. A. Gauglitz

March 2002

Prepared for the

U.S. Department of Energy

under Contract DE-AC06-76RL01830

and the Hanford Spent Nuclear Fuel Project

Managed by Fluor Hanford, Inc.

Pacific Northwest National Laboratory

Richland, WA 99352 


\section{Executive Summary}

The Hanford K-Basin sludge is to be retrieved and stored in the large-diameter containers (LDCs). This waste contains some fraction of uranium metal that generates hydrogen gas, which introduces potential upset conditions. One postulated upset condition is a rising plug of sludge supported by a hydrogen bubble that is driven into the vent filters at the top of the container. In laboratory testing with actual K-Basin sludge, vessel-spanning bubbles that lifted plugs of sludge were observed in 3-inch-diameter graduated cylinders.

This report presents a series of analytical assessments performed by Pacific Northwest National Laboratory to address the potential for the generation of a vessel-spanning bubble in the LDCs. The assessments included the development and evaluation of static and dynamic bubble formation models over the projected range of K-Basin sludge mechanical properties. Additionally, the theory of circular plates was extrapolated to examine conditions under which a plug of sludge would collapse and release a spanning bubble.

\section{Overall Conclusions}

Based on the conservative models developed in this report and on the latest mechanical property data of K-Basin sludge, the formation of vessel-spanning bubbles within LDCs is credible. This is due largely to the relatively high yield stress of K-Basin sludge, which could be as high as a few thousand Pascals. Vessel-spanning bubbles can form via two main mechanisms, from a single point source or from a uniformly distributed region of hydrogen-generating particles (uranium metal oxidation reaction). Effectively, a vessel-spanning bubble is a growing region occupied by gas that separates a lower hydrogen-generating sludge layer containing uranium metal from an overlying, mostly inert sludge layer.

Sludge plugs formed by spanning bubbles at yield stress measured for K-Basin sludges are predicted to be stable. Analysis based on thin circular plate theory showed that, if a sludge plug formed as a result of a vessel-spanning bubble, sludge batches with low yield stress are expected to collapse even for relatively thick plugs, thus preventing the sudden ejection of material from the container. However, as the yield stress increases beyond $100 \mathrm{~Pa}$, sludge collapse is expected to occur only for thin plugs.

\section{Key Findings}

Based on our vessel-spanning-bubble analysis, we conclude that the rheological behavior of K-Basin sludges, particularly the yield stress, is the dominant factor in determining bubble size. Assuming that the bubble is formed from a single-point source of gas generation and the rheological behavior of the sludge is described by the Herschel-Bulkley model for pseudoplastic materials, and using the conservative yield constant value of 0.061 , we predict that vessel- 
spanning bubbles will not form in 5-ft-diameter vessels provided the yield stress is less than $900 \mathrm{~Pa}$. For instance, the largest bubble size predicted for a sludge with a yield stress of $500 \mathrm{~Pa}$ is $3.2 \mathrm{ft}$. These conclusions do not exclude the formation of gas layers produced by a distributed gas-generating region within the sludge. If a gas-generating region spans the diameter of the vessel, a layer of gas will readily form and grow.

From a structural point of view, if a gas layer is formed, the overlying sludge "plug" could collapse due to 1) a sufficiently large bending moment that produces a state of stress within the plug that exceeds the yield stress of the material or 2) a gravitational instability that will amplify any imperfections at the solid-gas interface and/or any external vibrational disturbance.

Based on plate theory, if a gas layer spans the bottom of the vessel, sludge plugs at the worstcase overfill condition will collapse only if the yield stress of the sludge is $100 \mathrm{~Pa}$ or less. Otherwise, plugs will remain intact. However, this does not exclude the possibility of plug collapse due to gravitational instabilities.

Recent measurements of both floor and canister sludge samples revealed high yield stress, up to $12,000 \mathrm{~Pa}$. However, early measurements on discrete layers of floor sludge showed yield stress values of $10 \mathrm{~Pa}$ or less. Homogeneous mixtures of high and low yield stress sludge batches might attain a lower overall yield strength to a degree that is yet unknown. Compression and compaction will lead to an increase in yield stress, increasing the probability of a vesselspanning bubble.

An important finding of this study is that the dominant behavior of three distinct physical phenomena, namely bubble formation and detachment, plug failure due to bending moments, and plug failure due to gravitational instability, can be characterized with a single dimensionless parameter given by

$$
\mathrm{P}=\frac{\tau_{0}}{\rho \mathrm{gL}}
$$

where

$\tau_{0}=$ sludge yield stress

$\rho=$ sludge density

$\mathrm{g}=$ gravitational acceleration

$\mathrm{L}=$ characteristic length scale (bubble diameter, plug thickness, etc.).

Of course, for each physical situation, different constants apply, and other parameters, different for each situation, would be required for highly detailed descriptions. However, the leadingorder behavior for each one of these phenomena can be predicted by evaluating $\mathrm{P}$. 


\section{Acknowledgements}

The authors gratefully acknowledge the assistance and technical guidance of Andy Schmidt. He provided indispensable information, data, and valuable suggestions that materially improved this report. We thank Kurt Silvers for ensuring the continual flow of funding throughout the completion of this work. We also thank Paul Bredt and Adam Poloski for providing the latest measurements of K-Basin sludge yield stress and Sheila Bennett for her editorial support. 


\section{Contents}

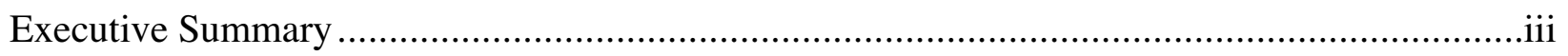

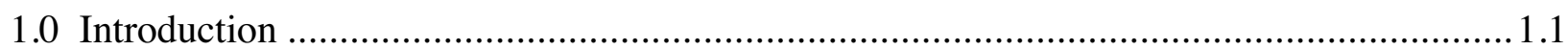

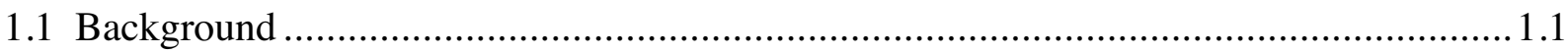

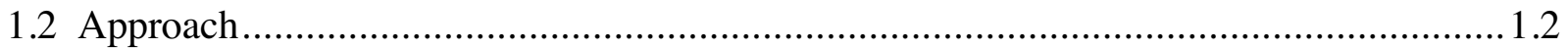

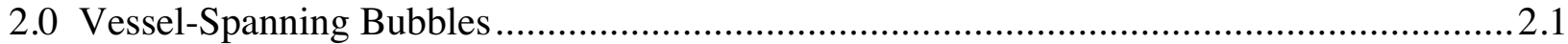

2.1 Laboratory Observations with KE Basin Canister Sludge ….........................................2.

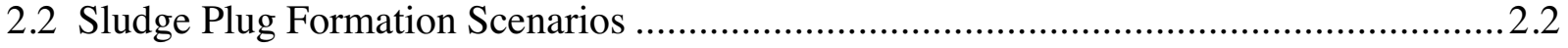

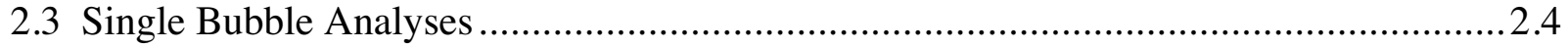

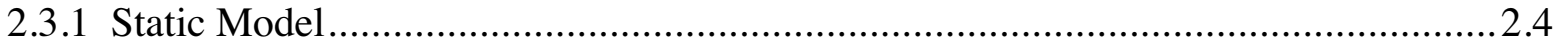

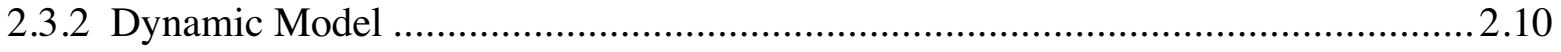

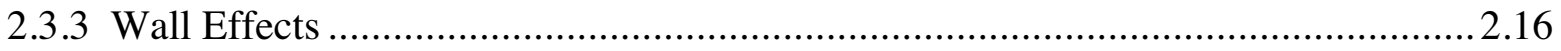

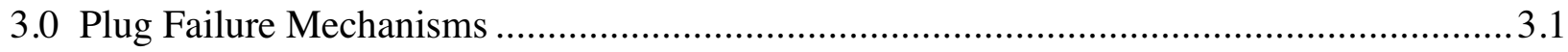

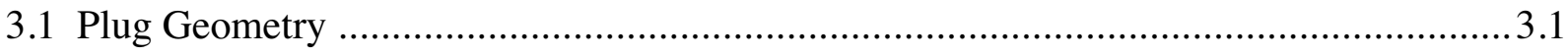

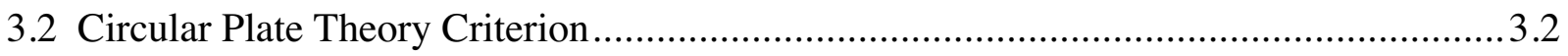

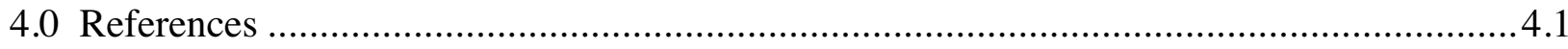

Appendix: Taylor Instability of a High-Strength Sludge Plug in a Storage Container .............. A.1 


\section{Figures}

2.1 Laboratory Observation of KE Sludge Plug Formation in Graduated Cylinder .................2.2

2.2 Possible Patterns of Bubble Formation in K Basin Sludge .........................................2.3

2.3 Typical Rheogram of KE Basin Sludge ............................................................ 2.5

2.4 Relative Bubble Size with Respect to the LDC Diameter ............................................2.9

2.5 Relative Bubble Size with Respect to LDC Diameter ..............................................2.15

3.1 Schematic of Idealized Nonuniform Sludge Plug Supported by Pressurized Gas Layer ..... 3.2

3.2 Schematic of the Plug-Plate Mass Imbalance Model Geometry and Dimensions ...............3.4

3.3 Plug-Plate Model Failure Diagram Showing Critical Thickness to

LDC Diameter Ratio as a Function of Plate Parameter ................................................ 3.5

\section{Tables}

2.1 Range of Parameters for Bubble Formation Analyses ........................................... 2.5

2.2 K Basin Sludge Shear Strength Data ....................................................................26

2.3 K Basin Sludge Shear Strength versus Settling Time .............................................2.7

2.4 Vessel-Spanning Bubble Calculations Based on Measured Densities and Upper Bound Yield Stress Using the Static Bubble Formation Model .......................... 2.10

2.5 Vessel-Spanning Bubble Calculations Based on Measured Densities and Upper Bound Yield Stress Using the Dynamic Bubble Formation Model 


\subsection{Introduction}

At the U.S. Department of Energy (DOE) Hanford Site in southeastern Washington State, a considerable amount of spent nuclear fuel (SNF) is stored in two water-filled concrete pools known as the K East (KE) and K West (KW) Basins. These basins in the $100 \mathrm{~K}$ Area contain over 2100 metric tons of N Reactor fuel elements in aluminum or stainless steel canisters. An estimated $52 \mathrm{~m}^{3}$ of sludge have accumulated in the canisters and on the floor of the K Basins. The sludge is believed to comprise a mixture of SNF, metal corrosion products, windblown particulate material, and other constituents such as organic and inorganic ion exchange material (Makenas et al. 1996, 1997, 1998, 1999). A detailed inventory and composition description of all K Basin sludge materials can be found in Pearce (2001). According to the SNF Project objectives, the sludge will be packaged, shipped, and stored at T Plant in the Hanford 200 Area until final processing at a future date.

\subsection{Background}

Gas generation within the $\mathrm{K}$ Basins has been reported and documented extensively (Johnson 1995; Baker et al. 2000; Bryan et al. 2001). We know that oxidation of metallic uranium is responsible for the generation of hydrogen gas within the K-Basin sludge. High rates of gas generation have been observed to occur in some K-Basin sludge samples. Experiments described by Baker et al. (2000) showed the formation of a large pocket of gas underneath a sludge sample from KE labeled 96-06. This observation was made during the course of a series of settling rate studies of K-Basin sludge samples in the laboratory. These authors reported that the level of gas generation from the $1996 \mathrm{KE}$ canister sludge samples was unexpectedly high. Sludge samples were placed in glass graduated cylinders $(7.6 \mathrm{~cm}$ in diameter) with water. After thoroughly mixing the contents with a helium sparging hose, the mixture was left to settle undisturbed. As a result of this batch sedimentation step, particulate settled, forming a stratified layer of sludge where the larger and denser particles remained at the bottom and smaller, less dense ones at the top. In this arrangement, uranium metal remained predominantly at the bottom of the layer. Approximately ten days after the sludge was sparged with helium, a gas bubble began to form at the bottom of one of the graduated cylinders. In time the bubble spanned the diameter of the cylinder, and the pressure buildup was enough to move the sedimented sludge layer upward. This was the first observed example of a vessel-spanning bubble.

With a vessel-spanning bubble observed in small laboratory experiments, a concern was raised about the possibility of vessel-spanning bubbles forming in those tanks used primarily to store floor, pit, and canister sludge. These storage vessels, known as large-diameter containers (LDC), are approximately $5 \mathrm{ft}$ in diameter and $10 \mathrm{ft}$ in height. Each LDC will include at least one passive filter vent. Through oxic and anoxic reaction pathways, hydrogen will be generated from the corrosion of uranium metal and further oxidation of the various species of uranium (Schmidt and Delegard 2002). The safety hazard of the formation of a vessel-spanning bubble 
lies in its potential to overflow or plug the vent system within the tank. Baker et al. (2000) suggested that a diagonal bar or other passive feature should be incorporated as part of the design to prevent the formation of vessel-spanning bubbles within LDCs.

\subsection{Approach}

In light of the experimental observations of sludge plugs in graduated cylinders, this study, performed by Pacific Northwest National Laboratory (PNNL) (under contract to Fluor Hanford Spent Nuclear Fuel Project), focuses on the formation scenarios of vessel-spanning bubbles in LDCs. Additional support to this report was provied by the Fluor Hanford Technology Management Office. This report describes models and presents calculations to quantify the largest-diameter bubble that can be held motionless within K-Basin sludge of varying shear strengths, rheological parameters, densities, and gas generation rates. The report also contains an analysis for the stability of a diameter-spanning sludge plug, again as a function of various physical properties and parameters. The results from this report will be used in design and safety basis calculations.

The first part of this report describes a model of bubble formation within a settled sludge layer, based on the assumption that all gas originates from a single point source. We assume that the bubble remains spherical during formation and detachment. Both of these assumptions led to a conservative model appropriate for safety analyses. Experimental data (Bredt et al. 1999) indicate that the $\mathrm{K}$ Basin sludge has a yield stress; thus, in the bubble formation analysis the sludge is treated as a yield pseudo-plastic (viscoplastic) material. Static as well as dynamic effects of bubble formation are considered in the analysis; thus, two separate models are used. In the static model, the bubble size is determined by a force balance between buoyancy and the "drag" force exerted on the bubble due to the sludge yield stress. Determination of the force that retains a buoyant sphere motionless has been the subject of several investigations (Chhabra 1993). In this study, a value for the drag force thought to be representative of most experimental observations was used in the calculations (Atapattu et al. 1995). In the dynamic model, the effect of gas generation rate is included in the analysis. This model is based on a generalization of a model for bubble formation and detachment developed and validated for Newtonian fluids by Kumar and Kuloor (1970).

In the second part of the report, plate theory is applied to cylindrical sludge plugs to determine their structural integrity based on a simple failure criterion. In this analysis, we assume that a vessel-spanning bubble has already formed. Thus, the gas pressure uniformly supports the resulting cylindrical plug. We assume that failure takes place via mass nonuniformity; i.e., that one side of the plug is heavier than the other. The validity of plate theory is strictly applicable to cylinder heights that are no larger than one-tenth of the cylinder diameter. Therefore, the results are used to provide an order of magnitude estimate of the critical height-to-diameter ratio that will lead to collapse as a function of the yield stress of the plug and the degree of mass imbalance. 
Plug failure could also occur in a perfectly balanced sludge cylinder with a perfectly planar bottom surface. In this instance, the failure mechanism is explained in terms of gravitational instability. A stability analysis of this kind was not included in the work scope for this report. During the course of this study, M. Epstein of Fauske \& Associates, Inc., prepared a letter report on the gravitational, or Taylor, instability that is included as an appendix to this report. Determining which failure mechanism (mass imbalance or gravitational instability) is the more unstable remains unresolved. 


\subsection{Vessel-Spanning Bubbles}

This section describes two models of bubble formation within a sludge based on the assumption that all gas originates from a single point source. Static as well as dynamic effects of bubble formation are considered in these analyses. Gas bubbles are assumed to remain spherical during the formation and detachment stages. Both of these assumptions lead to a conservative model appropriate for safety analyses. Experimental data (Schmidt et al. 2002; Bredt et al. 1999) indicate that K-Basin sludge material can withstand finite shear without appreciable deformation; i.e., it possesses shear strength. Therefore, the sludge is treated as a yield pseudo-plastic (viscoplastic) material. In the static model, the bubble size is determined by a force balance between buoyancy and the "drag" force exerted on the bubble due to the sludge yield stress. Several investigations (e.g., Chhabra 1993) have focused on determining the force that keeps a buoyant sphere motionless. In our calculations, we used a value for the drag force that we thought was representative of most experimental observations (Atapattu et al. 1995). In the dynamic model, the effect of gas generation rate is incorporated into the analysis. This model is based on a generalization of a model for bubble formation and detachment developed and validated for Newtonian fluids by Kumar and Kuloor (1970).

\subsection{Laboratory Observations with KE Basin Canister Sludge}

Detailed descriptions of observations of sludge plug formation in the laboratory can be found in Baker et al. (2000). Experiments with $1996 \mathrm{KE}$ canister sludge samples were conducted in glass graduated cylinders with a capacity of two liters and diameter and height of approximately 7.6 and $40.6 \mathrm{~cm}$, respectively (see Figure 2.1). Even though observations of gas generation from sludge located in KE indicated a very low level of hydrogen gas generation, the handling of sludge samples in the laboratory to study settling of particulate caused an unexpectedly high level of gas generation. In some instances, pressurization was observed when approximately $250 \mathrm{~mL}$ of sludge and $1000 \mathrm{~mL}$ of water were placed in graduated cylinders and left to settle for 10 days (samples were sparged twice to induce turbulent mixing prior to settling).

Effectively, batch sedimentation is a separation process whereby heavier and denser particles reach the bottom of the container before any other particle. This results in a gravitationally stable stratified layer of sludge. Sediment stratification of the sludge was reported by Baker et al. (2000) who visually identified up to three distinct layers: a top layer composed of submicron size particles, followed by a middle layer of particles of a few microns, and then a bottom layer of particles several hundred microns in diameter. In the cases where a sludge plug was lifted due to an increase in pressure, most of the gas generated originated from the bottom layer, where the concentration of metallic uranium particles was highest. 


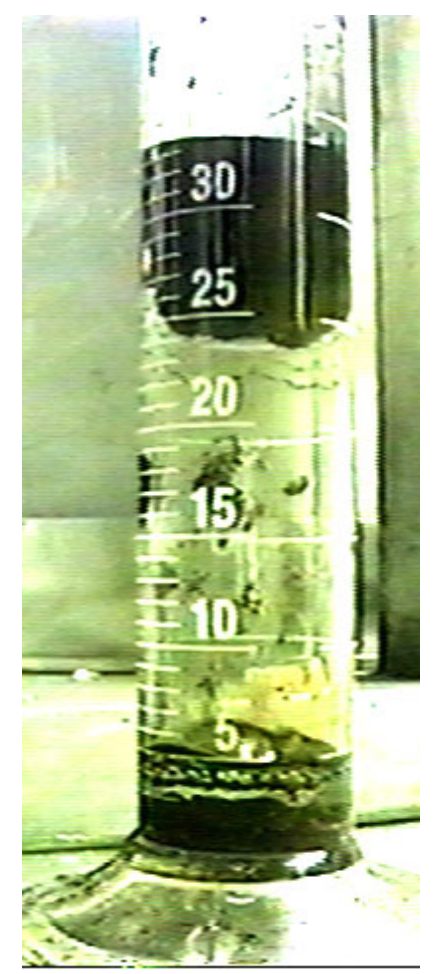

Figure 2.1. Laboratory Observation of KE Sludge Plug Formation in a Graduated Cylinder

\subsection{Sludge Plug Formation Scenarios}

Depending on the distribution of gas-generating particles, four main patterns of bubble formation can be distinguished in sludges. First, bubbles can originate from multiple point generation sources of gas within sludge of low yield stress. In this instance, relatively small bubbles (compared with the vessel diameter) will grow and move upward, easily overcoming the low yield stress of the material. Second, bubbles can originate from multiple point generation sources of gas within sludge of high yield stress. In this instance, bubbles will grow but will remain motionless for a longer period of time before they move upward, overcoming the high yield stress of the sludge. This situation could allow for coalescence with neighboring bubbles, forming larger bubbles that could potentially span the diameter of the containing vessel. Third, a single bubble could grow as a result of a large concentration of uranium metal particles in a small region of the vessel. In this scenario, bubble growth can be viewed as being dominated by a single point source, which, depending on the mechanical properties of the sludge and the gasgeneration rate, could lead to a vessel-spanning bubble. Fourth, a layer of gas could grow due to a uniformly distributed concentration of gas-generating particles over an area equal to the crosssectional area of the containing vessel. Strictly speaking, the term "bubble" is not appropriate in this case because the gas generated in this manner is not entirely bounded by the sludge from the time gas generation begins. However, this situation will still be referred to as a possible scenario of what has historically been named a vessel-spanning bubble. These four patterns are depicted schematically in Figure 2.2. 


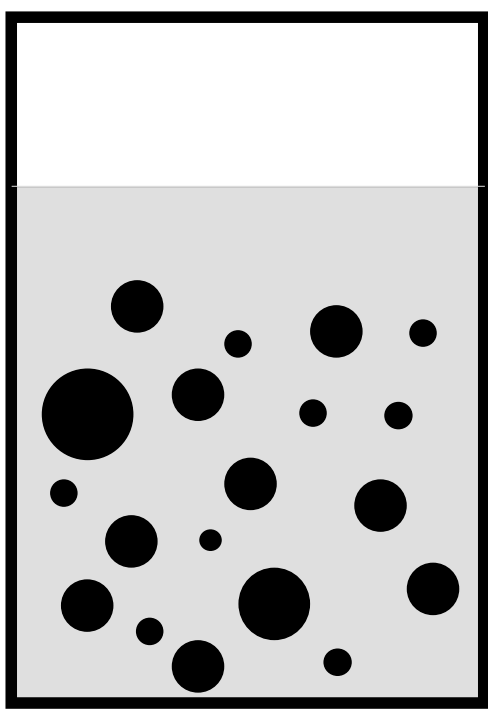

(a)

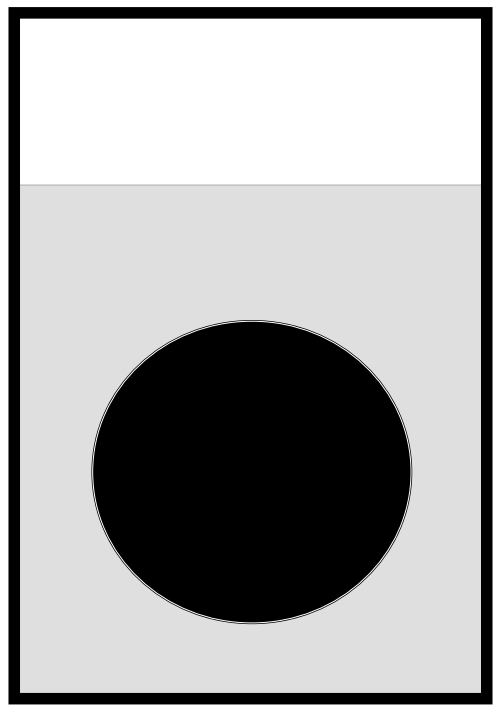

(c)

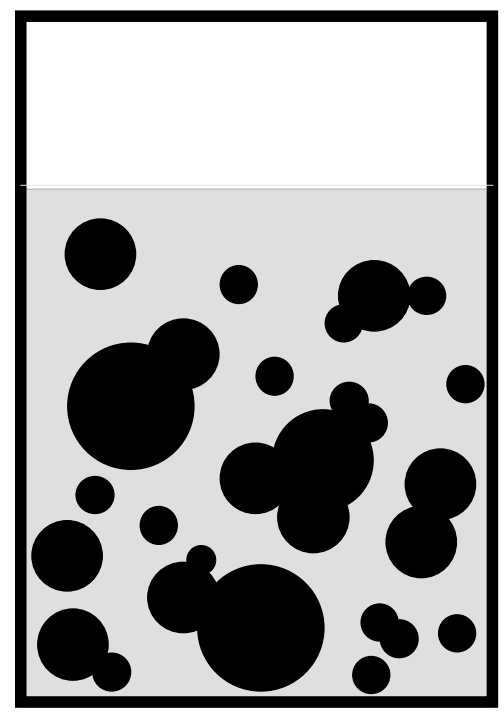

(b)

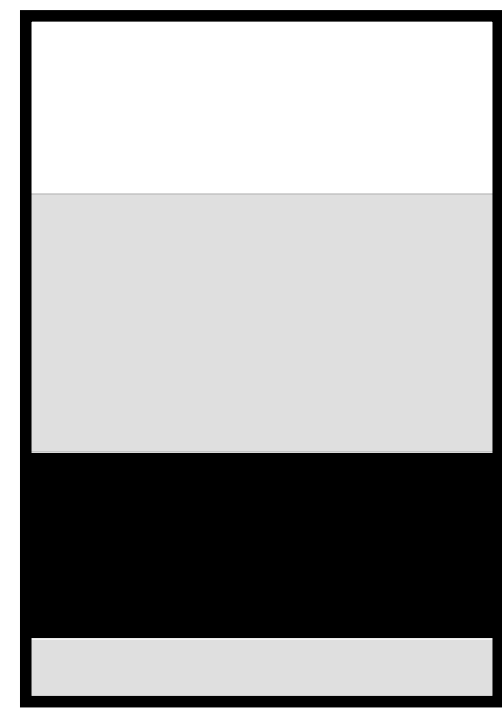

(d)

Figure 2.2. Possible Patterns of Bubble Formation in K Basin Sludge; a) multiple point source bubble formation in low yield stress sludge, b) multiple point source bubble formation in high yield stress sludge where coalescence may occur, c) single point source bubble formation as result of high concentration of uranium metal particles in a small region within the sludge, and d) gas layer growth due to a distributed concentration of uranium metal particles.

A critical safety issue that follows directly from laboratory observations is the possible formation of a vessel-spanning bubble in the containers that will be used to store floor, pit, and canister sludge. These storage vessels, or LDCs, are approximately $5 \mathrm{ft}$ in diameter and $10 \mathrm{ft}$ in height. Each LDC will include at least one passive filter vent. Through oxic and anoxic reaction 
pathways, hydrogen will be generated from the corrosion of uranium metal and further oxidation of the various species of uranium (Schmidt and Delegard 2002). The safety hazard of the formation of a vessel-spanning bubble lies in its potential to overflow or plug the vent system within the tank.

\subsection{Single Bubble Analyses}

In this section, the ability of a bubble to grow to span the entire diameter of a vessel is addressed. Two models are developed to provide conservative bounds on the maximum possible size of bubbles forming in K-Basin sludge for a wide range of rheological and mechanical properties. In these calculations we assume that gas is generated form single point source, which is one of several bubble formation scenarios discussed in the previous section. This scenario was chosen because its assumption of having all of the gas-generating material concentrated at one point makes it the most conservative. In addition, we assume that the bubble remains spherical during formation and detachment.

\subsubsection{Static Model}

Rheological measurements with viscometers and shear vanes (Schmidt et al. 2002; Bredt et al. 1999) have shown that the K-Basin sludge is a shear-thinning viscoplastic material whose rheological behavior can be characterized adequately with the Herschel-Bulkley model. Figure 2.3 shows a typical rheogram of KE Basin sludge (sample 96-06).

Table 2.1 shows the ranges of the physical parameters used in the first phase of analyses on the formation of bubbles within LDCs of K-Basin sludge (Crea 2001; Makenas et al. 1998; Bredt et al. 1999). ${ }^{\text {(a) }}$ Yield stress measurements of K-Basin sludge have been recorded since 1995. A detailed summary of measurements at specific locations within the $\mathrm{K}$ Basins under various loading conditions is shown in Table 2.2 (Bredt et al. 1999; Makenas et al. 1996, 1997, 1998). The most recent yield stress measurements are shown in Table 2.3.

In the static model of bubble formation, the bubble size is determined by a force balance between buoyancy and the "drag" force exerted on the spherical bubble due to the sludge yield stress. Surface tension effects are neglected because the focus in this report is on large bubbles. In reality, large bubbles deviate considerably from perfect spheres precisely because the interfacial force at the bubble boundary is small compared with other forces. Yet it is assumed that the bubble remains spherical.

(a) Irwin JJ (FHI). December 13, 2001. E-mail attachment sent to G Terrones: "T-Plant Thermal Model Property and Boundary Data." 


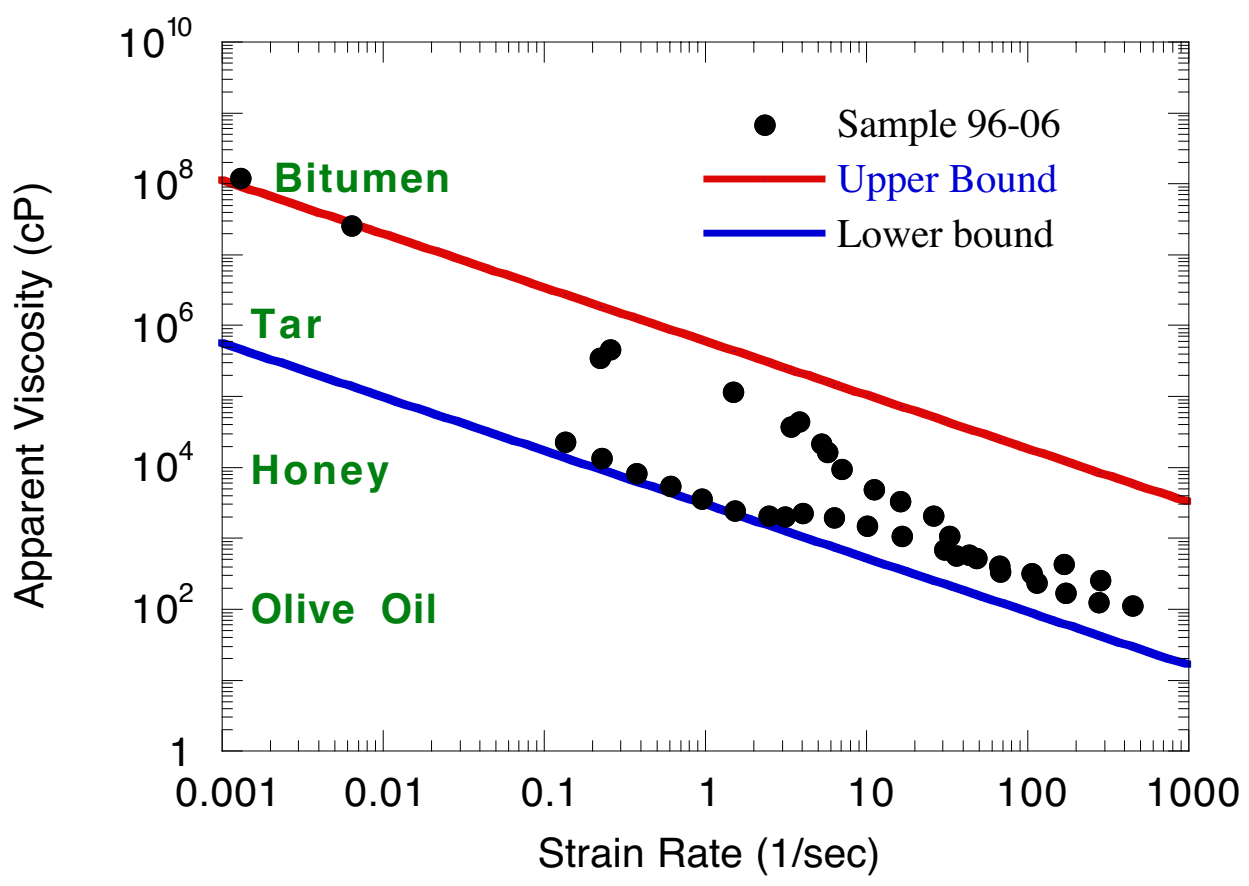

Figure 2.3. Typical Rheogram of KE Basin Sludge (sample 96-06). Straight lines are upper and lower bounds described by the Herschel-Bulkley model.

Table 2.1. Range of Parameters for Bubble Formation Analyses

\begin{tabular}{|l|l|}
\hline Wet Sludge Density & $1012-6200 \mathrm{~kg} / \mathrm{m}^{3}$ \\
\hline Sludge Yield Stress & $130-8200 \mathrm{~Pa}$ \\
\hline Gas Generation Rate & $10-28.2 \mathrm{ft}^{3} / \mathrm{day}$ \\
\hline Apparent Viscosity & $10^{3}-10^{8} \mathrm{cP}$ \\
\hline Behavior Index n (for Herschel-Bulkley model) & $0.2-0.28$ \\
\hline Consistency Factor (for Herschel-Bulkley model) & $20-600 \mathrm{~Pa} \mathrm{~s}^{\mathrm{n}}$ \\
\hline Vessel Diameter (LDC) & $1.524 \mathrm{~m}$ \\
\hline
\end{tabular}

Determining the drag force that keeps a buoyant sphere motionless continues to be the subject of investigation (Chhabra 1993). A relatively small number of experimental and theoretical studies have been performed on the dynamics of bubbles in non-Newtonian fluids compared with those in Newtonian fluids. An even smaller number of studies of bubble behavior in viscoplastic and soft solid materials (like the K Basin sludge) are available in the open literature. To date, no closed-form solution of the drag on a sphere in a viscoplastic medium has been developed. In our calculations, we use a value for the drag force that is thought to be representative of most experimental observations (Atapattu et al. 1995). 
Table 2.2. K Basin Sludge Yield Stress Data (1995 to 2001)

\begin{tabular}{|c|c|c|c|}
\hline Sample ID & Sample Description & $\begin{array}{c}\text { Yield } \\
\text { Stress } \\
(\mathbf{P a}) \\
\end{array}$ & $\begin{array}{l}\text { Settled } \\
\text { Density } \\
\left(\mathrm{g} / \mathrm{cm}^{\mathbf{3}}\right)\end{array}$ \\
\hline \multicolumn{4}{|c|}{$\begin{array}{l}1995 \text { KE Floor and Pits Sludge (Makenas et al. 1996) } \\
\text { (measured using Bolin Controlled Stress rheometer) }\end{array}$} \\
\hline KES-M-13 Top & Top strata of the KE floor sludge, described as "liquid like" & 2.2 & 1.11 \\
\hline KES-T-20 Top & Top strata of KE weasel pit sludge, described as "liquid like" & 0.9 & 1.6 (est.) \\
\hline \multicolumn{4}{|c|}{$\begin{array}{l}\text { 1996 KE Canister Sludge (Makenas et al. 1997) } \\
\text { (measured after two weeks of settling using a Haake M5 with 8-mm-diameter shear vane) }\end{array}$} \\
\hline $96-04 \mathrm{U} / \mathrm{L}$ & $\begin{array}{l}\text { Sample } 96-04 \text { settled into two layers, with } 70 \text { vol\% in the upper } \\
\text { layer and } 30 \text { vol\% in lower layer. 96-04 U/L was collected at } \\
\text { the interface between the upper and lower layerw. 96-04 was } \\
\text { collected from a canister containing very corroded fuel. }\end{array}$ & $<100$ & 1.09 \\
\hline 96-06 U/M & $\begin{array}{l}\text { Sample } 96-06 \text { settled into three distinct layers, with } 5 \text { vol\% in } \\
\text { the upper layer, } 53 \text { vol\% in middle layer, and } 42 \text { vol } \% \text { in the } \\
\text { lower layer. Sample } 96-06 \text { U/M was collected at the interface } \\
\text { of the upper and middle layers. 96-06 was collected from a } \\
\text { canister containing significantly corroded fuel. }\end{array}$ & $200 \pm 30$ & $\sim 1.7$ \\
\hline $96-06 \mathrm{M}$ & Middle layer of sample $96-06.83 \mathrm{wt} \% \mathrm{U}$ (dry basis) & $150 \pm 20$ & 1.92 \\
\hline $96-06 \mathrm{M} / \mathrm{L}$ & $\begin{array}{l}\text { Collected fro the interface of the middle and lower layer of } \\
\text { sample 96-06. }\end{array}$ & $460 \pm 40$ & $\sim 2.5$ \\
\hline 96-06 L & Lower layer of sample 96-06. $84 \mathrm{wt} \% \mathrm{U}$ (dry basis) & 470 & 2.99 \\
\hline 96-11 U/L & $\begin{array}{l}\text { Sample } 96-11 \text { settled into two distinct layers, with } 7 \text { vol\% in } \\
\text { the upper layer and } 93 \text { vol\% in the lower layer. } 96-04 \mathrm{U} / \mathrm{L} \text { was } \\
\text { collected at the interface between the upper and lower layers. } \\
96-11 \text { was collected from an unfueled canister. }\end{array}$ & 130 & $\sim 1.1$ \\
\hline \multicolumn{4}{|c|}{$\begin{array}{l}1996 \text { KW Canister Sludge (Makenas et al. 1998) } \\
\text { (measured after three days of settling using Bohlin Controlled Stress rheometer) }\end{array}$} \\
\hline 96-21 Rec & $\begin{array}{l}\text { Size fractionated subsample of 96-21 ( } 97 \mathrm{vol} \% \text { of original } \\
\text { sample) containing only particles less than } 710 \mu \mathrm{m}\end{array}$ & $30-40$ & 3.30 \\
\hline 96-24 Rec & $\begin{array}{l}\text { Size fractionated subsample of 96-24 (84 vol\% of original } \\
\text { sample) containing only particles less than } 710 \mu \mathrm{m}\end{array}$ & $20-30$ & 2.64 \\
\hline \multicolumn{4}{|c|}{$\begin{array}{l}1999 \text { Consolidated Sludge Samples (Bredt et al. 1999) } \\
\text { (measured after two weeks of settling using Haake M5 with 8-mm-diameter shear vane.) }\end{array}$} \\
\hline $\mathrm{KC}-2 / 3 \mathrm{M} 250$ & $\begin{array}{l}\text { Size fractionated canister sludge composite (sludge from } 11 \\
\text { canister barrels) containing only particles less than } 250 \mu \mathrm{m} .\end{array}$ & $280 \pm 110$ & 2.13 \\
\hline KC-4 P250 & $\begin{array}{l}\text { Size fractionated floor sludge (collected on floor between } \\
\text { slotted barrels) containing only particles greater than } 250 \mu \mathrm{m} \text {. }\end{array}$ & $\begin{array}{l}2800 \\
800\end{array}$ & 1.3 \\
\hline KC-4 M250 & $\begin{array}{l}\text { Size fractionated floor sludge (collected on floor between } \\
\text { slotted barrels) containing only particles less than } 250 \mu \mathrm{m} \text {. }\end{array}$ & $300 \pm 10$ & 1.2 \\
\hline KC-5 P250 & $\begin{array}{l}\text { Size fractionated floor sludge (collected on floor away from } \\
\text { corroded fuel) containing only particles greater than } 250 \mu \mathrm{m} \text {. }\end{array}$ & $\begin{array}{l}2700 \\
400\end{array}$ & 1.5 \\
\hline KC-5 M250 & $\begin{array}{l}\text { Size fractionated floor sludge (collected on floor away from } \\
\text { corroded fuel) containing only particles less than } 250 \mu \mathrm{m} \text {. }\end{array}$ & $270 \pm 20$ & 1.2 \\
\hline
\end{tabular}




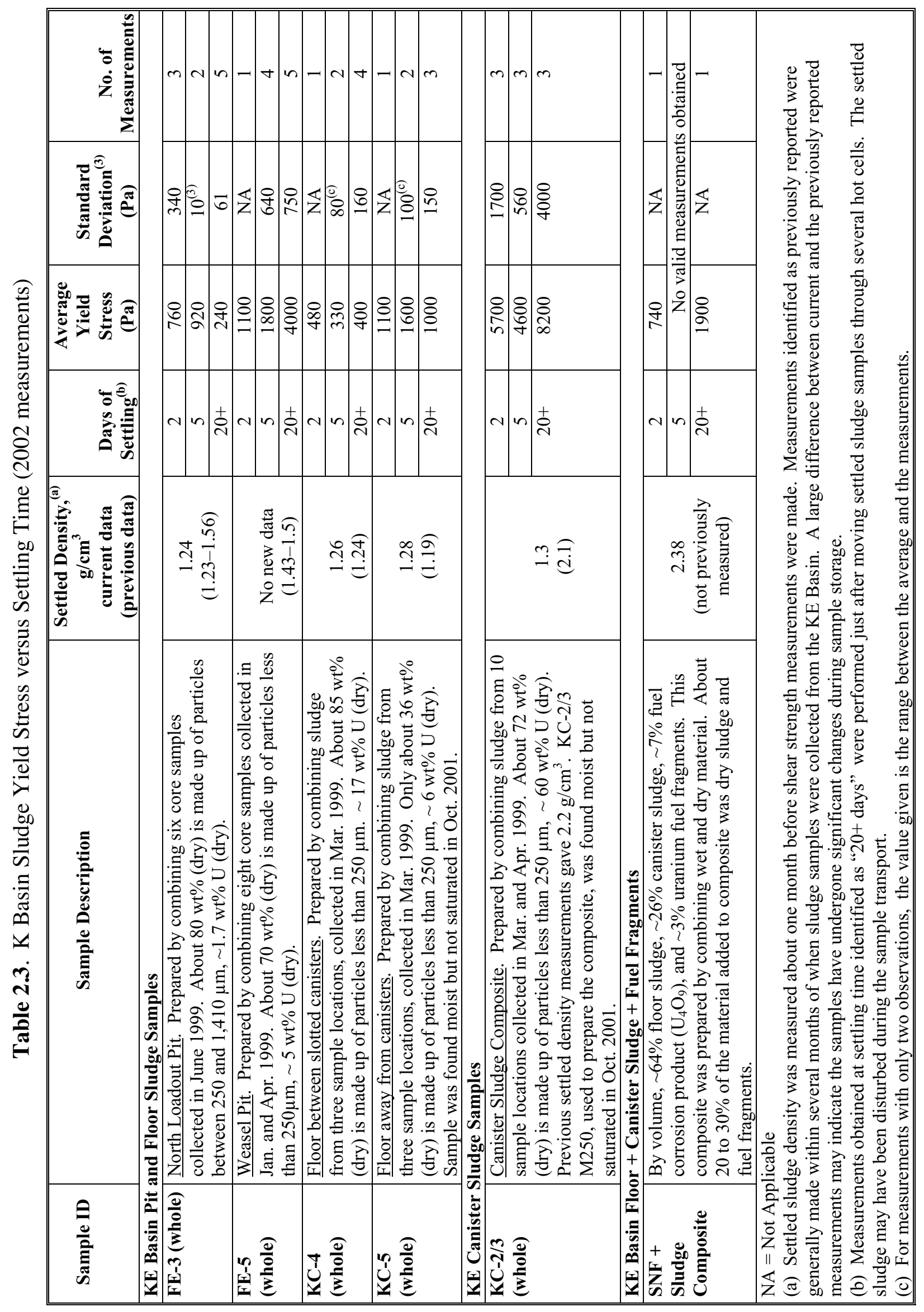


For a spherical bubble the buoyancy force $F_{b}$ is

$$
F_{b}=\frac{\pi}{6}\left(\rho-\rho_{g}\right) g d^{3}
$$

where

$\rho=$ sludge bulk density

$\rho_{\mathrm{g}}=$ gas density (hydrogen in this case)

$\mathrm{g}=$ gravitational acceleration

$\mathrm{d}=$ bubble diameter.

Adapting Atapattu's (1995) experimentally determined condition of no motion to a bubble retained in sludge, the total critical force, $F_{c}$, above which a bubble will overcome the yield stress and move upward is

$$
\mathrm{F}_{\mathrm{c}}=\frac{\pi \mathrm{d}^{2} \tau_{0}}{6 \mathrm{k}}
$$

where

$\tau_{0}=$ sludge yield stress

$\mathrm{k}=$ dimensionless yield constant.

Different values of $k$ have been reported in the literature (Chhabra 1993), ranging from 0.04 to 0.6. This wide range may be attributed to discrepancies in the definition of the yield stress of the material and the manner in which the experiments and yield stress measurement were conducted. Some authors use the Bingham while other use the Herschel-Bulkley model to define a yield stress. In addition, some authors measure $k$ starting from a moving sphere trying to determine the condition that will hold the sphere motionless, whereas others, starting with a motionless sphere, try to measure the condition that will produce motion. Furthermore, it appears that there is no universal value for $k$, but it is a function of the rheological properties of the medium. Analyses in this report are carried out using the value of 0.061 for the yield constant, as reported by Atapattu (1995).

To reduce the number of varying parameters that determine whether a bubble can rise through the sludge under static conditions (i.e., without taking into account the rate of generation of hydrogen), a dimensionless number can be obtained from the ratio between the critical force and the buoyancy force on the bubble. From Equations 2.1 and 2.2, this leads to the dimensionless parameter, $\mathrm{N}_{\mathrm{S}}$, given by

$$
\mathrm{N}_{\mathrm{S}}=\frac{\tau_{0}}{\mathrm{k}\left(\rho-\rho_{\mathrm{g}}\right) \mathrm{gd}}
$$


A bubble overcomes the yield stress of the sludge if $\mathrm{N}_{\mathrm{S}}>1$ and the condition at the onset of motion requires that $\mathrm{N}_{\mathrm{S}}=1$. To compare the bubble size relative to the $1.524 \mathrm{~m}(5 \mathrm{ft})$ diameter of the LDC at the onset of motion, the following relationship is used

$$
\frac{\mathrm{d}}{\mathrm{D}}=\frac{\tau_{0}}{\mathrm{k}\left(\rho-\rho_{\mathrm{g}}\right) \mathrm{gD}}
$$

where $D$ is the diameter of the LDC. Equation 2.4 is plotted in Figure 2.4, where the ordinate and abscissa are the left- and right-hand-side of this equation, respectively. This graphical representation of the relative bubble size allows the user to readily estimate the likelihood of encountering a vessel-spanning bubble within an LDC containing sludge of known density and yield stress. Because the density of gas is at least three orders of magnitude smaller than that of the sludge, the dimensionless number that the user would need to calculate to estimate the relative size of the bubble is $\tau_{0} /(\mathrm{k} \rho \mathrm{gD})$. In the static model it is assumed that a bubble will continue to grow, regardless of how or why, until it either becomes buoyant or spans the diameter of the LDC. From the point of view of static bubble formation, a vessel-spanning bubble will occur for sludge yield stress values in excess of $1000 \mathrm{~Pa}$.

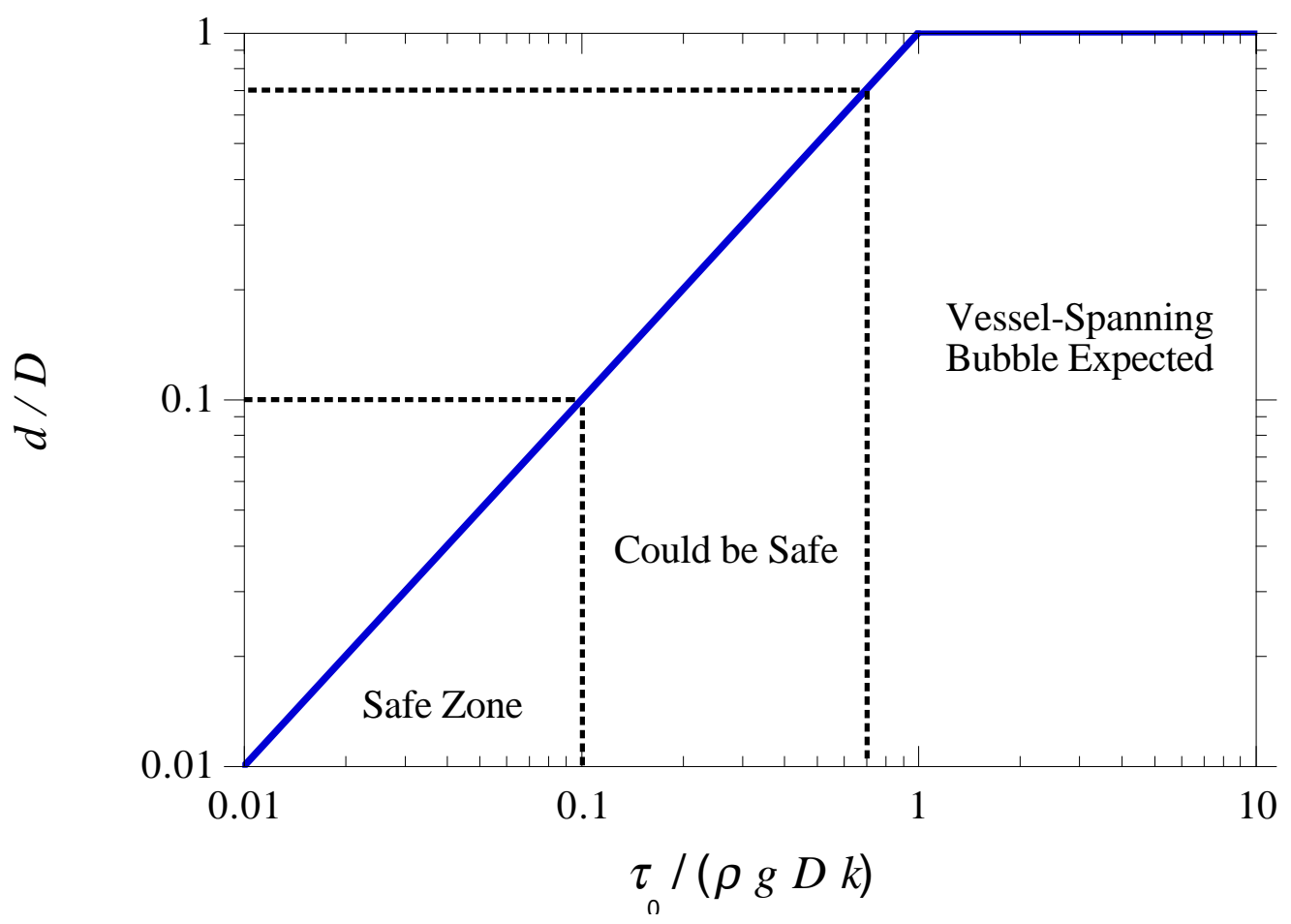

Figure 2.4. Relative Bubble Size with Respect to LDC Diameter 
Table 2.4. Vessel-Spanning Bubble Calculations Based on Measured Densities and Upper Bound Yield Stress Using the Static Bubble Formation Model

\begin{tabular}{|c|c|c|c|c|}
\hline Sample ID & $\begin{array}{c}\text { Settled } \\
\text { Density } \\
\left(\mathbf{g} / \mathbf{c m}^{\mathbf{3}}\right)\end{array}$ & $\begin{array}{c}\text { Yield Stress } \\
\text { Upper Bound } \\
(\mathbf{P a})\end{array}$ & $\frac{\boldsymbol{d}}{\boldsymbol{D}}$ & $\begin{array}{c}\text { Vessel-Spanning } \\
\text { Bubble? }\end{array}$ \\
\hline FE-3 & 1.24 & 1,100 & 0.9727 & Very Likely \\
\hline FE-5 & 1.43 & 4,750 & 3.6423 & Yes \\
\hline KC-4 & 1.26 & 560 & 0.4873 & No \\
\hline KC-5 & 1.28 & 1,700 & 1.4563 & Yes \\
\hline KC-2/3 & 1.30 & 12,200 & 10.290 & Yes \\
\hline
\end{tabular}

\subsubsection{Dynamic Model}

A dynamic model was developed to determine how the gas generation rate influences the size of a bubble being formed within the sludge. This model enables us to estimate how much larger a bubble will become as a result of a constant rate of gas generation. In reality, the gas generation rate is a function of time because, as the uranium metal is depleted through oxidation, the rate of gas production within the sludge decreases. Thus, the assumption of constant gas generation rate is conservative. As in the static model, the bubble is assumed to remain spherical throughout.

The dynamic model is a generalization of a model for bubble formation and detachment developed by Kumar and Kuloor (1970) (see also Chhabra 1993). Their model and its variants (with surface tension effects) are in excellent agreement with experimental observation of bubble formation processes in Newtonian fluids. This model is based on an initial expansion stage followed by a detachment stage. During the expansion stage, the bubble grows from a fixed point source of gas in such a way that base of the bubble remains at rest. The second stage begins when the bubble base starts moving upward while still connected to the gas source through a thin conduit. Therefore, during the second stage, the bubble continues to grow prior to final detachment. The physical basis for this model is that the actual detachment process of a bubble from a source begins with a spherical bubble that becomes increasingly elongated in the vertical direction as it grows. Because the idealized model assumes perfect spherical bubbles, the actual continuous volume growth of the bubble must be accounted for in the model with the assumption that the bubble grows spherically but is linked to a source of gas by an imaginary conduit until final detachment occurs.

At the end of the first stage, the buoyancy and opposing forces are in equilibrium. During the detachment stage, buoyancy dominates and the bubble begins to rise. Within the model assumptions, the detachment time $\mathrm{T}$ takes place when the bubble base during the second stage 
has traversed a length equal to the radius of the bubble of volume $V_{1}$ reached at the end of the first stage. The final volume of the bubble, $\mathrm{V}_{2}$, is

$$
\mathrm{V}_{2}=\mathrm{V}_{1}+\mathrm{QT}
$$

where $\mathrm{Q}$ is the gas generation rate (in $\mathrm{m}^{3} / \mathrm{s}$ ), and $\mathrm{V}_{1}$ is calculated from Equation (2.4)

$$
\mathrm{V}_{1}=\frac{\pi}{6}\left\lfloor\frac{\tau_{0}}{\mathrm{k}\left(\rho-\rho_{\mathrm{g}}\right) \mathrm{g}}\right]^{3}
$$

During the detachment stage, the bubble experiences two opposing forces: 1) drag due to the bubble vertical displacement and 2) the reaction force that the fluid exerts as a result of the rate of change of momentum due to expansion. Even in the absence of viscosity, there is a force associated with the expansion of a bubble, the net effect of which is calculated from the virtual mass, M, of the bubble (Kumar and Kuloor 1970) given by

$$
\mathrm{M}=\frac{11 \rho \mathrm{V}(\mathrm{t})}{16}
$$

where $\mathrm{V}(\mathrm{t})$ is the instantaneous bubble volume at time $\mathrm{t}$ (measured after the end of the first stage). At any time $t$, the bubble radius $r(t)$ is

$$
r(t)=\left[\frac{3\left(V_{1}+Q t\right)}{4 \pi}\right]^{1 / 3}
$$

The velocity of the bubble center of mass, $\mathrm{u}_{\mathrm{cm}}(\mathrm{t})$, is the sum of the velocity of the bubble at the base, $\mathrm{u}(\mathrm{t})$, and the velocity due to the rate of expansion, $\mathrm{dr}(\mathrm{t}) / \mathrm{dt}$. After differentiation and some algebra, it can be shown that the rate of change of momentum of the detaching bubble is

$$
\frac{\mathrm{d}\left(\mathrm{Mu}_{\mathrm{cm}}\right)}{\mathrm{dt}}=\frac{11 \rho \mathrm{Q}^{2}}{192 \pi}\left[\frac{4 \pi}{3\left(\mathrm{~V}_{1}+\mathrm{Qt}\right)}\right]^{2 / 3}
$$

where

$$
\frac{d\left(M u_{c m}\right)}{d t}=M(t) \frac{d u(t)}{d t}+u(t) \frac{d M(t)}{d t}+\frac{d}{d t}\left(M(t) \frac{d r(t)}{d t}\right)
$$


The velocity, $u(t)$, is the rate of change in vertical displacement of the bubble base during detachment, $\mathrm{x}(\mathrm{t})$ [i.e., $\mathrm{u}(\mathrm{t})=\mathrm{dx}(\mathrm{t}) / \mathrm{dt}$ ]. Applying Newton's second law to the detaching bubble, we obtain

$$
\frac{\mathrm{d}\left(\mathrm{Mu}_{\mathrm{cm}}\right)}{\mathrm{dt}}=\rho g\left(\mathrm{~V}_{1}+\mathrm{Qt}\right)-\mathrm{F}_{\mathrm{D}}
$$

where $\mathrm{F}_{\mathrm{D}}$ is the drag force for a sphere moving in a viscoplastic medium. From Atapattu's (1995) experimental correlation of the drag coefficient of a sphere in a Herschel-Bulkley fluid, the drag force is

$$
\mathrm{F}_{\mathrm{D}}=12 \pi \mathrm{r}^{2}\left[\mathrm{a} \tau_{0}+\mathrm{X}(\mathrm{n}) \eta\left(\frac{\mathrm{u}}{\mathrm{d}}\right)^{\mathrm{n}}\right\rceil
$$

where a is a constant of order one that depends on the rheology of the material and for which several values have been postulated in the literature, $\eta$ is the consistency factor, $n$ is the behavior index, and $\mathrm{X}(\mathrm{n})$ is the drag correction factor computed by Gu and Tanner (1985). Their results can be fitted to the following function:

$$
X(n)=\frac{c_{1}+c_{2} n+c_{3} n^{2}+c_{4} n^{3}}{1+c_{5} n+c_{6} n^{2}+c_{7} n^{3}}
$$

with the corresponding coefficient values of

\begin{tabular}{|c|c|}
\hline Constant & Value \\
\hline $\mathrm{c}_{1}$ & 1.290728601 \\
\hline $\mathrm{c}_{2}$ & -0.66416093 \\
\hline $\mathrm{c}_{3}$ & 13.94828967 \\
\hline $\mathrm{c}_{4}$ & -10.8519716 \\
\hline $\mathrm{c}_{5}$ & -0.87641226 \\
\hline $\mathrm{c}_{6}$ & 9.308756042 \\
\hline $\mathrm{c}_{7}$ & -5.71381689 \\
\hline
\end{tabular}

which has a correlation coefficient of 0.99968 .

At the onset of detachment $(t=0)$,

$$
\mathrm{u}_{\text {onset }}=\frac{\mathrm{dr}(\mathrm{t})}{\mathrm{dt}}=\frac{\mathrm{Q}}{4 \pi}\left(\frac{4 \pi}{3 \mathrm{~V}_{1}}\right)^{2 / 3}
$$


and using Equations 2.7 to 2.14, the force balance becomes

$$
\frac{11 \rho Q^{2}}{192 \pi}\left(\frac{4 \pi}{3 \mathrm{~V}_{1}}\right)^{2 / 3}+12 \pi \mathrm{r}^{2}\left[\mathrm{a} \tau_{0}+\mathrm{X}(\mathrm{n}) \eta\left(\frac{\mathrm{Q}}{6 \mathrm{~V}_{1}}\right)^{\mathrm{n}}\right]=\rho \mathrm{gV}_{1}
$$

Therefore, the condition at the onset of detachment leads to Equation 2.15, from which the constant a can be evaluated in terms of all the known parameters:

$$
\mathrm{a}=\frac{1}{18 \mathrm{k}}-\frac{\mathrm{X}(\mathrm{n}) \eta}{\tau_{0}}\left(\frac{\rho \mathrm{gk}}{\tau_{0}}\right)^{3 \mathrm{n}}\left(\frac{\mathrm{Q}}{\pi}\right)^{\mathrm{n}}-\frac{11}{144 \pi^{2}}\left(\frac{\rho \mathrm{gk}}{\tau_{0}}\right)^{4} \frac{\rho \mathrm{Q}^{2}}{\tau_{0}}
$$

In Equation (2.16) the positive term is dominant and very close to unity (0.911), as expected from experimental observations (Atapattu 1995). A conservative estimate for the hydrogen generation rate in and LDC is $9.24 \times 10^{-6} \mathrm{~m}^{3} / \mathrm{s}\left(28.2 \mathrm{ft}^{3} /\right.$ day) (Crea et al. 2001; Bryan et al. 2001). Thus, for very low gas generation rates and yield stresses on the order of $1000 \mathrm{~Pa}$, the last term in Equation (2.16) is negligible. To reduce the number of parameters, the following dimensionless variables are introduced:

$$
\begin{aligned}
& \theta=\frac{\mathrm{Q}}{\mathrm{V}_{1}} \mathrm{t} \\
& \mathrm{z}=\left(\frac{4 \pi}{3 \mathrm{~V}_{1}}\right)^{1 / 3} \mathrm{x}
\end{aligned}
$$

together with the following dimensionless numbers:

$$
\begin{aligned}
& \left.\mathrm{N}_{1}=\frac{\tau_{0}}{\mathrm{X}(\mathrm{n}) \eta} \mid \frac{\pi}{\mathrm{Q}}\left(\frac{\tau_{0}}{\rho \mathrm{gk}}\right)^{3}\right]^{\mathrm{n}} \\
& \mathrm{N}_{2}=\frac{11 \rho}{16 \tau_{0}}\left(\frac{\mathrm{Q}}{\pi}\right)^{2}\left(\frac{\rho \mathrm{gk}}{\tau_{0}}\right)^{4}
\end{aligned}
$$

Therefore, the dimensionless governing equation for the bubble motion during detachment can be written as 


$$
\mathrm{N}_{2} \frac{\mathrm{d}^{2} \mathrm{z}}{\mathrm{d} \theta^{2}}+\frac{\mathrm{N}_{2}}{1+\theta} \frac{\mathrm{dz}}{\mathrm{d} \theta}+\frac{\left[1+3(1+\theta)^{2 / 3} \frac{\mathrm{dz}}{\mathrm{d} \theta}\right]^{\mathrm{n}}}{\mathrm{N}_{1}(1+\theta)^{\mathrm{n}+1 / 3}}+\frac{\mathrm{N}_{2}}{9(1+\theta)^{5 / 3}}+\frac{\mathrm{a}}{(1+\theta)^{1 / 3}}=\frac{1}{18 \mathrm{k}}
$$

For the level of gas generation rates expected to take place in K-Basin sludge, assuming a worst-case scenario $\left(9.24 \times 10^{-6} \mathrm{~m}^{3} / \mathrm{s}\right)$, the dimensionless number $\mathrm{N}_{2}$ is negligible. Physically, this is equivalent to neglecting inertial effects due to a very slow expansion rate. Therefore, all terms in Equation 2.21 multiplied by $\mathrm{N}_{2}$ are vanishingly small provided $\tau_{0}$ is larger than $100 \mathrm{~Pa}$. Lesser values of $\tau_{0}$ are of no interest for the present calculations because, under such conditions, smaller bubbles can be formed that would overcome the strength of the material. In the chosen nondimensionalization, $\tau_{0}$ is implicitly assumed to be different than zero. When the gas generation rate is low, the constant $a$ in Equation 2.16 can be written as

$$
a=\frac{1}{18 k}-\frac{1}{N_{1}}
$$

These simplifications lead to a first-order nonlinear differential equation involving a single dimensionless group:

$$
3(1+\theta)^{2 / 3} \frac{\mathrm{dz}}{\mathrm{d} \theta}=\left\{\mathrm{N}\left[(1+\theta)^{1 / 3}-1\right]+1\right\}^{1 / \mathrm{n}}(1+\theta)-1
$$

where $\mathrm{N}=\mathrm{N}_{1} / 18 \mathrm{k}$. Spatially, the limits of integration of Equation 2.23 run from zero to a distance equal to the radius of a bubble of volume $V_{1}$. Temporally, the limits run from zero to $\mathrm{T}$ as stipulated in Equation 2.5. After nondimensionalizing these limits, the final volume $V_{2}$ and thus the length scale of the bubble is obtained upon integration of

$$
\int_{\mathrm{z}=0}^{\mathrm{z}=1} \mathrm{dz}=\frac{1}{3} \int_{\theta=0}^{\theta=\gamma^{3}-1}(1+\theta)^{-2 / 3}\left[\left\{\mathrm{~N}\left[(1+\theta)^{1 / 3}-1\right]+1\right\}^{1 / \mathrm{n}}(1+\theta)-1\right] \mathrm{d} \theta
$$

where $\gamma$ is the ratio between the bubble volume at the end of the detachment stage and the bubble volume obtained from purely static conditions. Equation 2.24, which can be integrated in closed form (but it is not transcribed here because the expression is quite lengthy), leads to a nonlinear equation to be solved numerically for $\gamma$. Finally, the value length scale of the bubble under dynamic conditions is

$$
\left(\frac{\mathrm{d}}{\mathrm{D}}\right)_{\text {Dynamic }}=\gamma(\mathrm{N})\left(\frac{\mathrm{d}}{\mathrm{D}}\right)_{\text {Static }}
$$


Figure 2.4 shows the results of applying the dynamic model to sludge of $500 \mathrm{~Pa}$ and shearthinning parameters given in Table 2.1. Figure 2.5 compares the relative bubble diameters calculated based on the static and dynamic models of bubble formation. The effect of gasgeneration rate in the dynamic model produces a larger-diameter bubble than its static counterpart, as shown by the dashed curve in the figure. This effect is more pronounced in sludge with low yield stress. As the yield stress increases, the dynamic model calculations asymptotically approach those based on the static model. Specific examples of calculations with the dynamic model are shown in Table 2.5. From the point of view of dynamic bubble formation, a vessel-spanning bubble will occur for sludge yield stress values in excess of $800 \mathrm{~Pa}$.

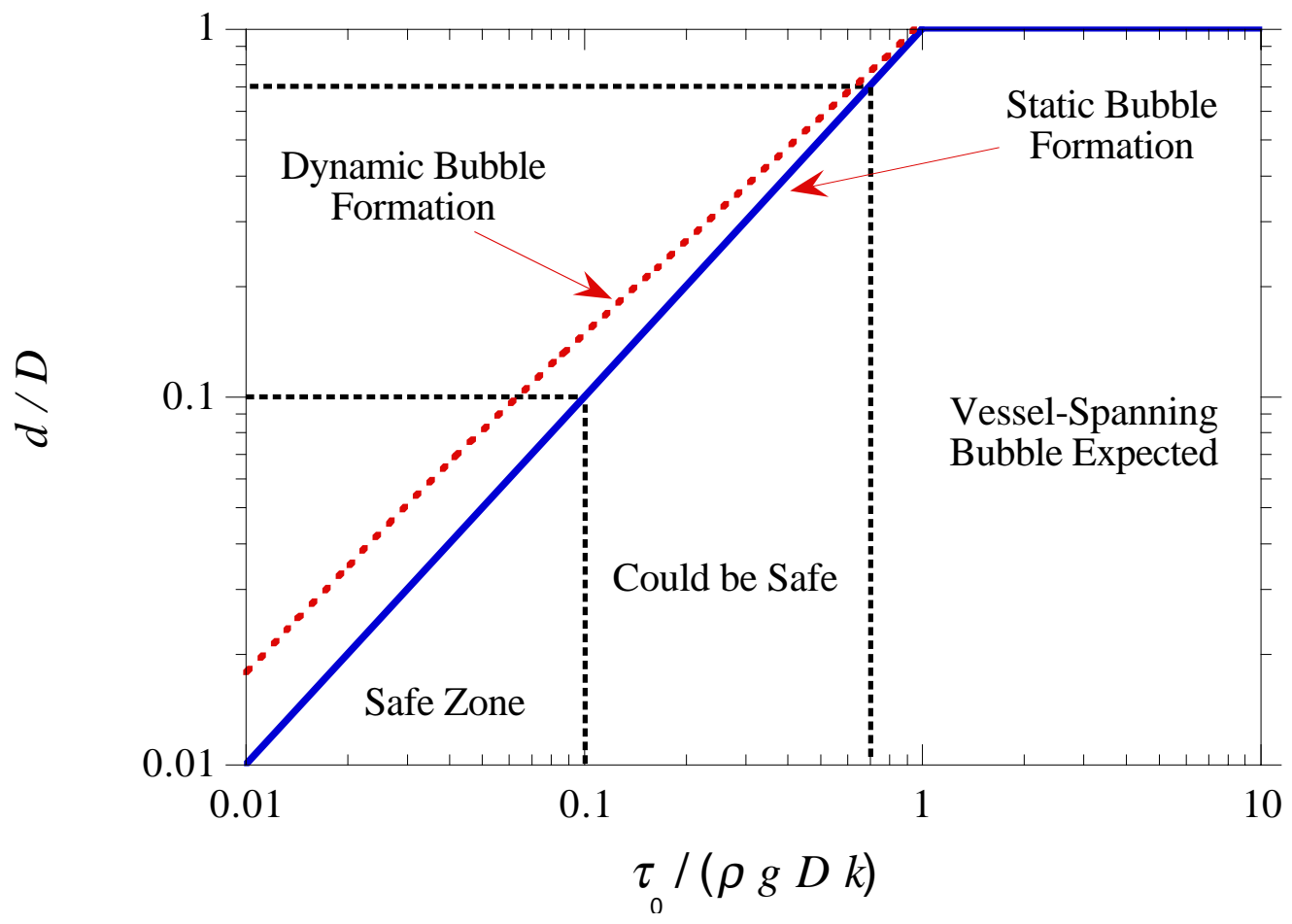

Figure 2.5. Relative Bubble Size with Respect to LDC Diameter

Table 2.5. Vessel-Spanning Bubble Calculations Based on Measured Densities and Upper Bound Yield Stress Using the Dynamic Bubble Formation Model

\begin{tabular}{|c|c|c|c|c||}
\hline Sample ID & $\begin{array}{c}\text { Settled } \\
\text { Density } \\
\left(\mathbf{g} / \mathbf{c m}^{\mathbf{3}}\right)\end{array}$ & $\begin{array}{c}\text { Yield Stress } \\
\text { Upper Bound } \\
(\mathbf{P a})\end{array}$ & $\frac{\boldsymbol{d}}{\boldsymbol{D}}$ & $\begin{array}{c}\text { Vessel-Spanning } \\
\text { Bubble? }\end{array}$ \\
\hline FE-3 & 1.24 & 1,100 & 1.0222 & Yes \\
\hline FE-5 & 1.43 & 4,750 & 3.6750 & Yes \\
\hline KC-4 & 1.26 & 560 & 0.5406 & No \\
\hline KC-5 & 1.28 & 1,700 & 1.5011 & Yes \\
\hline KC-2/3 & 1.30 & 12,200 & 10.316 & Yes \\
\hline
\end{tabular}




\subsubsection{Wall Effects}

In Newtonian fluids, bubble formation, detachment, and motion are influenced by the neighboring boundaries. In these fluids, any deformation in the flow field is affected by the solid boundaries because of the ellipticity of the equations of motion under low Reynolds number conditions (i.e., information on fluid motion is transmitted instantaneously throughout the fluid domain). However, in viscoplastic fluids, information is spread over a yielded region within the fluid domain, the extent of which is determined by the generalized form of the Reynolds number that accounts for the yield stress of the medium.

During the expansion phase of a bubble caused by low gas-generation rate, the yield stress of the viscoplatic fluid is exceeded only within a thin symmetrical region in the neighborhood of the bubble. A similar situation occurs during the detachment phase of the bubble except that the yielded region loses its symmetry due to vertical translation. Beaulne and Mitsoulis (1997) computed the yielded region of a translating sphere through a viscoplastic medium bounded by a cylindrical wall. Effectively, a slowly expanding or moving bubble is unaffected by the presence of solid boundaries unless the gap between the bubble and the wall is less than $10 \%$ of the radius of the bubble. The slower the motion, the thinner the yielded region will become. 


\subsection{Plug Failure Mechanisms}

In this section, plate theory is applied to cylindrical sludge plugs to determine their structural integrity based on a simple failure criterion. In this analysis, we assume a vessel-spanning bubble has already formed. Thus, the gas pressure uniformly supports the resulting cylindrical plug. In addition, we assume that failure takes place via an assumed heterogeneous distribution of mass throughout the plug; i.e., one side of the plug is heavier than the other. The validity of plate theory is strictly applicable to cylinder heights that are no larger than one-tenth of the cylinder diameter. Therefore, the results are used to provide an order of magnitude estimate of the critical height-to-diameter ratio that will lead to collapse as a function of the yield stress of the plug and the degree of mass imbalance.

Plug failure could also occur in a perfectly balanced sludge cylinder with a perfectly planar bottom surface. In this instance, the failure mechanism is explained in terms of a gravitational instability. When a vessel-spanning bubble is formed, the overlying plug is structurally unstable because the density of the sludge is more than three orders of magnitude larger than the density of the gas. While the strength of the material tends to keep the integrity of the plug intact, the size and density of the plug tend to destabilize its structure. This is reminiscent of the RayleighTaylor stability problem for fluids, in which a liquid can be held in a cylindrical container upside down if the diameter of the container is small enough for the stabilizing effect of surface tension to dominate. While a stability analysis of this kind is not within the scope of this report, we did include a report on the gravitational, or Taylor, instability by Fauske and Associates, Inc., as an appendix. Fauske's report was done concurrently with our report. The growth or decay of gravitational instabilities depended on the same dimensionless group (Equation 2.3) used in the single bubble analyses. Which failure mechanism (mass imbalance, gravitational instability, or other mechanism) is the most unstable remains an open question.

\subsection{Plug Geometry}

Uniformly distributed gas generation over a cross-section at the bottom of the sludge could reach a level of pressurization that would eventually make the plug act as a piston by lifting any overlying material. Experimental observation of forming plugs in graduated cylinders (see Figure 2.1) shows that the gas-plug interface is not perfectly planar but somewhat irregular. Different degrees of irregularity were observed at the interface varying from slight to pronounced roughness. If the interface were fitted to a plane (i.e., take an average of the peaks and valleys of the rough surface), the result would be a tilted planar interface, as shown in Figure 3.1 .

The water-plug interface is planar provided its formation followed a batch sedimentation

process from a homogenously mixed water-particulate system. This interface is also subjected to 


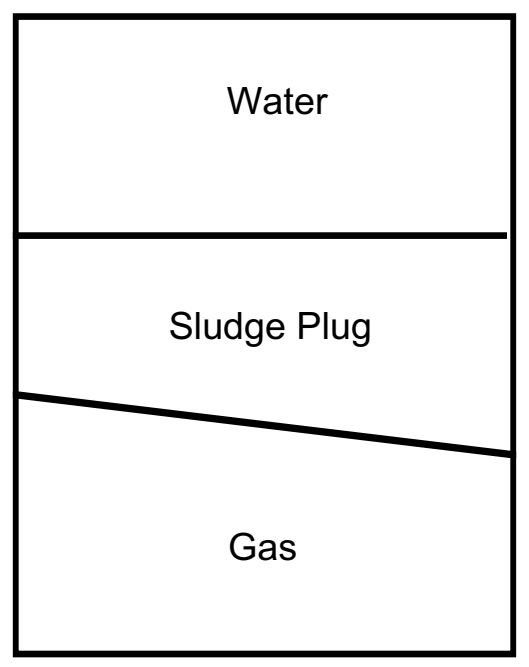

Figure 3.1. Schematic of an Idealized Nonuniform Sludge Plug fully Supported by the Pressurized Gas Layer

uniform pressure due to the hydrostatic head from the water column above it. Within the framework of plate theory, failure of the idealized plug depicted in Figure 3.1 would arise from a bending moment caused by the nonuniform distribution of mass. Circular plate theory yields accurate answers if the thickness of the plate is no more that one-tenth the diameter. Therefore, we applied this theory to the structural integrity K-Basin sludge plugs to understand at least some of the relevant scaling parameters that govern failure. Precise answers could be obtained only through numerical integration of the equilibrium equations for a plug of arbitrary thickness and given elastic and plastic parameters. An analysis of this nature is beyond the scope of this work.

\subsection{Circular Plate Theory Criterion}

For a nonuniformly loaded circular plate where the load occurs over a prescribed region on the plate or is distributed over the entire plate according to a simple function (linear, quadratic, etc.), closed-form solutions exist based on the linear theory of elasticity for the maximum radial and azimuthal stresses (Young and Budynas 2002; Pilkey 1994). To apply plate theory directly to the sludge plug, we assume that the loaded region of the plate corresponds to the region of the plug where the mass imbalance is located (see Figure 3.2). In other words, the weight of the excess mass is the driving force responsible for the bending moment.

To determine the critical ratio between the plug thickness and the diameter of the LDC, a yield criterion is required. Yield criteria depend on the mechanical properties of the material to which they are applied and also on the loading conditions. A first-order estimate is provided by the simplest possible yield criterion, namely, that plug collapse takes place when the maximum stress, $\sigma_{\max }$, in the plate is equal to or greater than the shear strength of the sludge, $\tau_{0}$, that is, 


$$
\sigma_{\max } \geq \tau_{0}
$$

According to plate theory, the functional form for the maximum yield stress in a nonuniformly loaded circular plate is

$$
\sigma_{\max }=\lambda \mathrm{w}\left(\frac{\mathrm{D}}{\mathrm{H}}\right)^{2}
$$

where

$\lambda=$ constant that depends on the shape and area of the loaded region and on boundary conditions (i.e., simply supported edge, fixed edge, etc.)

$\mathrm{w}=$ load per unit area

$\mathrm{H}=$ plug thickness

$\mathrm{D}=$ plug diameter.

Figure 3.2 shows side and top views of a plug with mass excess on the right. The weight of the excess mass per unit area, and thus the load that gives rise to the bending moment on the plugplate model, is

$$
\mathrm{w}=\rho \mathrm{gfH}
$$

where $f$ is the fraction of the plug thickness that quantifies the degree of the mass imbalance (see Figure 3.2). Substituting Equation 3.3 into 3.2 and invoking the yield criterion, the plug will collapse if

$$
\mathrm{H} \leq \frac{\mathrm{f} \lambda \rho \mathrm{gD}}{\tau_{0}}
$$

Values of $\lambda$ do not vary appreciably for simply supported or fixed-edge boundary conditions, but increase with the area of the loaded region. For a loaded area of up to half the area of the circle, values of $\lambda$ range between 0.03 and 0.15 . Scaling the plug height with the LDC diameter then, at the onset of failure, Equation 3.4 can be written as

$$
\frac{\mathrm{H}}{\mathrm{D}}=\left(\frac{\tau_{0}}{\mathrm{f} \lambda \rho \mathrm{gD}}\right)^{-1}
$$



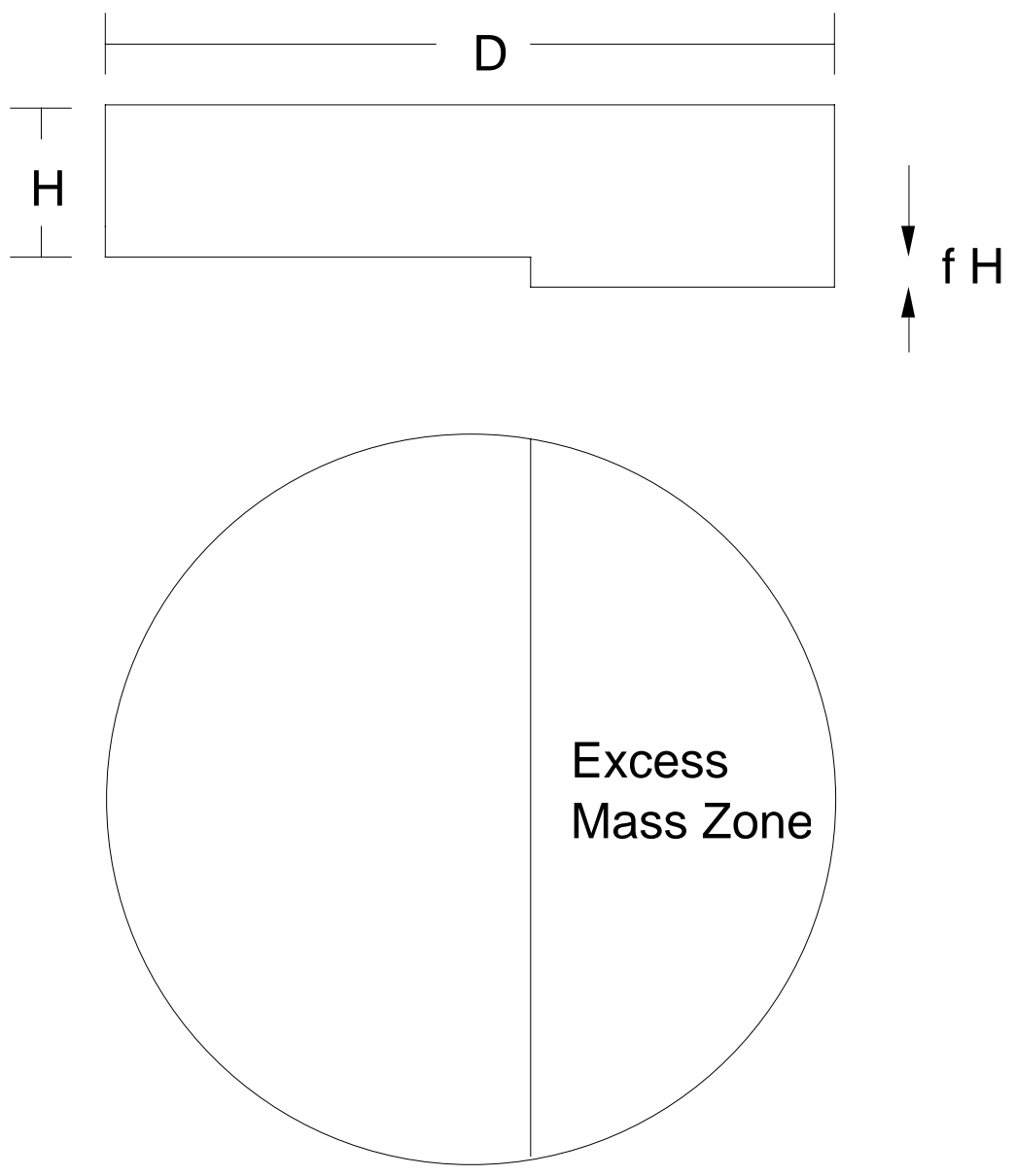

Figure 3.2. Schematic of the Plug-Plate Mass Imbalance Model Geometry and Dimensions

Equations 2.4 and 3.5 have essentially the same dimensionless number (except for a different constant relevant to each physical situation). Figure 3.3 plots the relative height of the plug with respect to the LDC diameter. All cases denoted by dots in Figure 3.3 were calculated by assuming a sludge average density of $1300 \mathrm{~kg} / \mathrm{m}^{3}$, and the constant $\lambda$ was 0.08 . The dashed line represents a fill condition of $3 \mathrm{~m}^{3}$. Cases in Figure 3.3 to the left of the critical failure line (solid curve) are stable plugs within the assumption of plate theory. Sludge batches with low yield stress are expected to collapse even for relatively thick plugs, preventing the sudden ejection of material from the container. However, as the yield stress increases beyond $100 \mathrm{~Pa}$, collapse is expected only for thin plugs. 


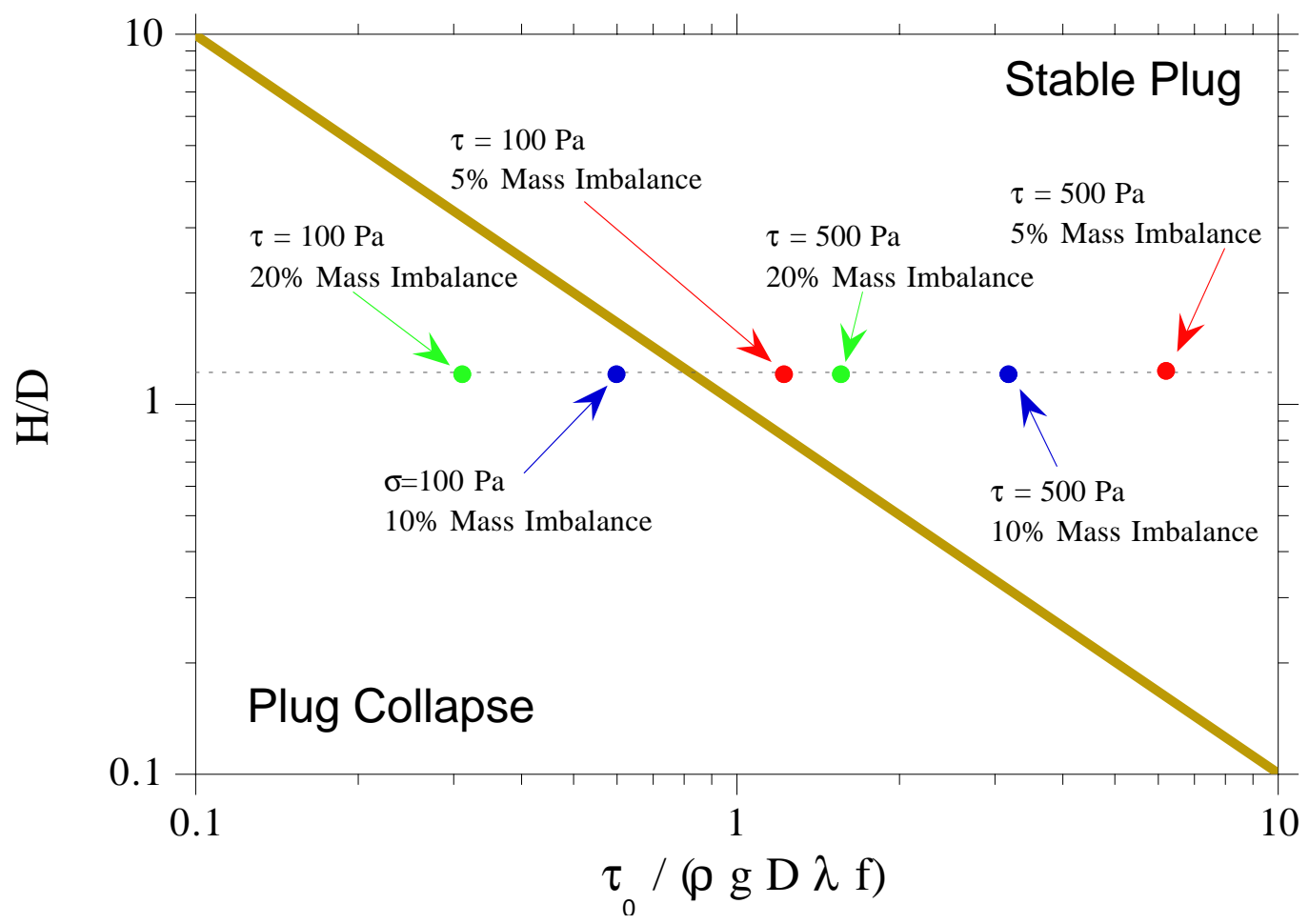

Figure 3.3. Plug-Plate Model Failure Diagram Showing Critical Thickness to LDC Diameter Ratio as a Function of Plate Parameter

When a gas layer is formed via a growing bubble that spans the vessel, then, from Equation 2.4, a bubble forms if the tank diameter is

$$
\mathrm{D}=\frac{\tau_{0}}{\rho \mathrm{gk}}
$$

Substituting Equation 3.6 into 3.4, the condition for the collapse of a plug is given in terms of the plate "constant" and the constant for the no-motion condition of a spherical bubble in a viscoplastic sludge

$$
\frac{\mathrm{H}}{\mathrm{D}} \leq \frac{\mathrm{f} \lambda}{\mathrm{k}}
$$

where a typical value for the ratio of constants $(\lambda / \mathrm{k})$ is on the order of 1.3 . 


\subsection{References}

Atapattu DD, RP Chhabra, and PHT Uhlherr. 1995. "Creeping sphere motion in HerschelBulkley fluids: flow file and drag." J. Non-Newtonian Fluid Mech. Vol. 59, pp. 245-265.

Beaulne M and E Mitsoulis. 1997. "Creeping motion of a sphere in tubes filled with HerschelBulkley fluids.” J. Non-Newtonian Fluid Mech. Vol. 72, pp. 55-71.

Baker RB, BJ Makenas, and JA Pottmeyer. 2000. Observations of K Basins Sludge Behavior in Relation to Sludge Container Design and Storage at T Plant. HNF-6705 Rev. 0, Fluor Hanford, Inc., Richland, Washington.

Bredt PR, CH Delegard, AJ Schmidt, and KL Silvers. 1999. Testing and Analysis of Consolidated Sludge Sample from 105K East Basin Floor and Canisters. PNNL-13341, Pacific Northwest National Laboratory, Richland, Washington.

Bryan SA, CH Delegard, AJ Schmidt, RL Sell, KL Silvers, SR Gano, and BM Thornton. 2001. Gas Generation from K East Basin Sludges-Series II Testing. PNNL-13446, Pacific Northwest National Laboratory, Richland, Washington.

Chhabra RP. 1993. Bubbles, Drops, and Particles in Non-Newtonian Fluids. CRC Press, Boca Raton, Florida.

Crea BA, FJ Heard, S Hecht, JJ Irwin, and K Sathyanarayana. 2001 Preliminary Thermal Analysis Report for KE Basin Sludge Storage Container. SNF-8356, Fluor Hanford, Inc., Richland, Washington.

Gu D and RI Tanner. 1985. "The Drag on a Sphere in a Power-Law Fluid." J. Non-Newtonian Fluid Mech. Vol. 17, pp. 1-12.

Johnson AB. 1995. k Basin Corrosion Program Report. WHC-EP-0877, Westinghouse Hanford Company, Richland, Washington.

Kumar R and NR Kuloor. 1970. "The Formation of Bubbles and Drops." Advances in Chemical Engineering Vol. 8, pp. 255-368.

Makenas BJ, TL Welsh, RB Baker, DR Hansen, and GR Golcar. 1996. Analysis of Sludge from Hanford K East Basin Floor and Weasel Pit. WHC-SP-1182, Westinghouse Hanford Company, Richland, Washington. 
Makenas BJ, TL Welsh, RB Baker, EW Hoppe, AJ Schmidt, J Abrefah, JM Tingey, PR Bredt, and GR Golcar. 1997. Analysis of Sludge from Hanford K East Basin Canisters. HNF-SP1201, DE\&S Hanford, Inc., Richland, Washington.

Makenas BJ, TL Welsh, RB Baker, GR Golcar, PR Bredt, AJ Schmidt, and JM Tingey. 1998. Analysis of Sludge from Hanford K West Basin Canisters. HNF-1728 Rev. 0, Fluor Daniel Hanford, Richland, Washington.

Makenas BJ, TL Welsh, PR Bredt, GR Golcar, AJ Schmidt, KL Silvers, JM Tingey, AH Zacher, and RB Baker. 1999. Analysis of Internal Sludge and Cladding Coatings from N-Reactor Fuel Stored in Hanford K Basins. HNF-3589 Rev. 0, Fluor Daniel Hanford, Richland, Washington.

Pearce KL. 2001. 105-K Basin Material Design Basis Feed Description for Spent Nuclear Fuel Project Facilities, Volume 2, Sludge. HNF-SD-SNF-TI-009 Rev. 4, Fluor Hanford, Inc., Richland, Washington.

Pilkey WD. 1994. Formulas for Stress, Strain, and Structural Matrices. John Wiley and Co., New York.

Schmidt, AJ and CH Delegard. 2002. Assessment of K Basin Sludge Volume Expansion Resulting from Uranium Corrosion During Storage. PNNL-13786, Pacific Northwest National Laboratory, Richland, Washington.

Young WC and RG Budynas. 2002. Roark's Formulas for Stress and Strain. McGraw-Hill, New York. 


\title{
Appendix
}

\section{Taylor Instability of a High-Strength Sludge Plug in a Storage Container}

\author{
M. Fauske
}

Note:

This appendix is included, with permission of the author, to assist the reader. Its contents have not been peer reviewed, but the results seem reasonable. 
Fauske \& Associates, Inc.

DATE: January 11, 2002

TO: $\quad$ M. G. Plys

FROM: $\quad$ M. Epstein

SUBJECT: Taylor Instability of a High-Strength Sludge Plug in a Storage Container

If most of the reactive uranium metal settles out at the bottom of a $\mathrm{K}$ basic storage container a reaction-product (container-spanning) gas layer may form above the metal layer and expand against the overlying, relatively deep layer of inert sludge.* If the inert sludge layer remains stable as the gas layer continues to expand, sludge material will ultimately reach and pass through the vent located at the top of the storage container. On the other hand, the development of buoyancy forces due to the presence of the underlying light gas layer may render the sludge layer laterally unstable to infinitesimal disturbances at the gas/sludge layer interface. Unstable disturbances will grow into gas spikes which penetrate the overlying sludge layer and result in the disintegration of the sludge layer.

Analysis of the type of sludge disintegration mechanism described above is traceable to Taylor. This is the well-known "Taylor instability", which is known to occur in fluids when accelerated either by gravity or by inertia in a direction perpendicular to an interface across which there is a discontinuity in density, provided that the acceleration is directed from the less dense fluid into the more dense fluid. In the fluid interface problem, consideration of capillarity effects leads to a minimum size interface disturbance (wave) below which no unstable waves are generated (Bellman and Pennington, 1954). Similarly, we anticipate that the presence of sludge strength stabilizes short interface wavelength perturbations.

\footnotetext{
*Recent particle settling calculations (Plys, 2001) that fully account for realistic sludge feed rates into the storage container preclude the formation of a single, bottom layer of high reactive metal concentration beneath a deep layer of inert sludge. However, a stratified sludge morphology involving many thin layers containing reactive metal particles "sandwiched" between relatively thick layers of inert material is possible.
} 
Miles (1966) applied the method of generalized coordinates to the problem of Taylor instability in solids in the small perturbation (linear) range, assuming the solid material is homogeneous and incompressible. He assumed a single degree of freedom system and that the solid material obeys the Prandtl-Reuss constitutive equations for yielded plastic solids (see, e.g. Prager and Hodge, 1951), with the yield stress and shear modulus G as constitutive parameters. Miles found that the growth history of a two-dimensional surface wave of initial amplitude $\eta_{0}$ having initial wavelength $\lambda$ on the surface of a solid being accelerated by a gas is

$$
\eta=\eta_{0} \exp (\mathrm{mt})
$$

where

$$
\mathrm{m}=\left[\mathrm{k}(\mathrm{g}+\mathrm{a})-\frac{13}{4} \frac{\mathrm{G}}{\rho} \mathrm{k}^{2}\right]
$$

In the above equations $\eta$ is the instantaneous amplitude of the wave at time $t, \rho$ is the density of the solid, $\mathrm{g}$ is the acceleration due to gravity, "a" is the imposed acceleration, $\mathrm{m}$ is the growth constant, and $\mathrm{k}$ is the wave number of the disturbance:

$$
\mathrm{k}=\frac{2 \pi}{\lambda}
$$

Barnes et al. (1974) performed an experimental and numerical study of Taylor instability in solids. In their experimental study radiographs were taken of the surface of a plate accelerated by the detonation products of a high explosive. A sinusoidal wave pattern (perturbation) was machined or pressed into the surface of the plate that was in contact with the detonation products. The observed increase of the amplitude of the perturbations with time demonstrated that Taylor instability occurs in solids. The theoretical portion of their study consisted of running a two-dimensional Lagrangion elastic-plastic code. The observed perturbation growth history was compared with the code calculations and it was concluded by Barnes et al. that the perturbation growth was sensitive to the 
dynamic yield stress $\tau_{\mathrm{dyn}}$ of the solid material and was insensitive to the shear modulus G. They recommended the following formula for the growth constant in Eq. (1):

$$
\mathrm{m}=\left[\mathrm{k}(\mathrm{g}+\mathrm{a})-\mathrm{f}\left(\tau_{\text {dyn }}, \mathrm{k}\right)\right]^{1 / 2}
$$

where $\mathrm{f}$ was determined to be a linear function of $\tau_{\text {dyn }}$ with $\mathrm{f}=0$ at $\tau_{\text {dyn }}=0$.

Apparently, Barnes et al. did not carry out enough calculations to determine the dependency of f on k. From dimensional considerations and Eq. (2) one would expect

$$
\mathrm{f}\left(\tau_{\mathrm{dyn}}, \mathrm{k}\right) \sim \frac{\tau_{\mathrm{dyn}}}{\rho} \mathrm{k}^{2}
$$

Therefore it is proposed here that

$$
m=\left[k(g+a)-C \frac{\tau_{d y n}}{\rho} k^{2}\right]^{1 / 2}
$$

where $\mathrm{C}$ is as yet and unknown numerical coefficient. The numerical coefficient can be inferred from the calculations and measured results presented by Barnes et al. (1974) for an aluminum plate. The wavelength machined into the plate was $\lambda=0.508 \mathrm{~cm}$. The corresponding wave number is $\mathrm{k}=$ $1.24 \times 10^{3} \mathrm{~m}^{-1}$ (see Eq. 3). The plate acceleration was a $\simeq 10^{9} \mathrm{~m} \mathrm{~s}^{-1}$. The calculations showed that wave growth was suppressed when the yield strength exceeded approximately $\tau_{\text {dyn }} \simeq 4 \mathrm{kbar}\left(4 \times 10^{8}\right.$ $\mathrm{Pa})$. From Eq. (6) wave growth is stable $(\mathrm{m}=0)$ for $\mathrm{k}$ greater than the critical value

$$
\mathrm{k}_{\mathrm{crit}}=\frac{\rho(\mathrm{g}+\mathrm{a})}{\mathrm{C} \tau_{\mathrm{dyn}}}
$$

or by solving for $\mathrm{C}$ 


$$
C=\frac{\rho(g+a)}{k_{c r i t} \tau_{d y n}}
$$

Inserting the experimental and theoretical parameter values mentioned in the foregoing into Eq. (8) gives $\left(\rho=2700 \mathrm{~kg} \mathrm{~m}^{-3}\right.$ for $\mathrm{Al}$ and $\left.\mathrm{g}<<\mathrm{a}\right)$

$$
C=\frac{(2700)\left(10^{9}\right)}{\left(1.24 \times 10^{3}\right)\left(4 \times 10^{8}\right)}=5.44
$$

- The coefficient $\mathrm{C}$ can also be inferred from the measured perturbation growth history. Barnes et al. reported a growth constant $\mathrm{m}=2.51 \times 10^{5} \mathrm{~s}^{-1}$ for aluminum with an initial perturbation wave number $\mathrm{k}=1.24 \times 10^{3} \mathrm{~m}^{-1}$. The plate acceleration was $\mathrm{a}=10^{9} \mathrm{~m} \mathrm{~s}^{-2}$ and the code calculation with $\tau_{\mathrm{dyn}}=3.25 \times 10^{8} \mathrm{~Pa}$ gave the best match to the experimental wave amplitude versus time curve. Solving Eq. (6) for $\mathrm{C}$ and substituting the measured and calculated parameters into the result gives

$$
\begin{aligned}
\mathrm{C} & =\frac{\rho}{\tau_{\mathrm{dyn}} \mathrm{k}^{2}}\left(\mathrm{ka}-\mathrm{m}^{2}\right)=\frac{2700}{\left(3.25 \times 10^{8}\right)\left(1.24 \times 10^{3}\right)^{2}}\left[\left(1.24 \times 10^{3}\right)\left(10^{9}\right)-\left(2.51 \times 10^{5}\right)^{2}\right] \\
& =6.36
\end{aligned}
$$

which is in substantial agreement with the inference given by Eq. (9). It would appear that a satisfactory estimate is $\mathrm{C} \approx 6$ so that the formula for the wave-amplitude growth constant is (see Eq. 6)

$$
\mathrm{m}=\left[\mathrm{k}(\mathrm{g}+\mathrm{a})-6 \frac{\tau_{\mathrm{dyn}}}{\rho} \mathrm{k}^{2}\right]^{1 / 2}
$$

Before we apply Eq. (11) to the problem of sludge plug stability, it is useful to briefly discuss the dynamic yield stress. It is well known that each material has its own value of the yield stress under purely dynamic conditions (see, e.g., Blake, 1965). The yield stress increases with increasing rate of strain. Therefore, the dynamic yield stress is greater than the static yield stress. The effect of 
strain rate on yield strength is more important for low strength materials than for high-strength materials. For example soft $1100-0$ aluminum possesses a static yield strength of $\sim 0.3 \mathrm{kbar}$ and a dynamic yield strength of about 3.3 kbar. The difference between the static and dynamic yield strengths of strong 6061-T5 aluminum is not nearly so great, $2.5 \mathrm{kbar}$ static versus $3.3 \mathrm{kbar}$ dynamic. It is assumed here that the yield strength $(\tau)$ values reported for viscoplastic sludge materials may be identified with the dynamic yield stress of purely solid materials since in both cases for stress levels greater than the yield stress the material structure disintegrates and behaves like a fluid. For Bingham-like non-Newtonian materials the dynamic yield stress is determined from the y intercept of a shear stress versus shear rate curve generated by viscometer data and is the yield stress used in rheological models.

For the sludge plug problem the imposed acceleration $\mathrm{a}=0$ and the critical wave number for sludge instability is, from Eq. (7) or from Eq. (11) with $\mathrm{m}=0$,

$$
\mathrm{k}_{\text {crit }}=\frac{\rho g}{6 \tau}
$$

where $\rho$ and $\tau$ are, respectively, the density and yield stress of the sludge material. It follows that the critical wavelength at the onset of sludge plug instability is (see Eq. 3)

$$
\lambda_{\text {crit }}=\frac{12 \pi \tau}{\rho g}
$$

Equation (13) implies that the initial velocity of the perturbation is high enough for the perturbation to grow through the early-time elastic regime that exists when the perturbation amplitude is small. The critical wavelength given by Eq. (13) can be interpreted as the critical wavelength for sludge breakup by the growth of perturbations at the lower surface of the sludge plug as it is being displaced by the growing gas layer. The perturbations are gradually transformed from linear sinusoidal waves to round-ended gas columns that penetrate the sludge. The bubble columns ultimately terminate the upward motion of the sludge plug by "breaking through" the upper (stable) surface of the plug. Since the sludge plug is bounded laterally by the walls of the storage container, an upper limit is imposed 
to the admissible wavelength. Equation (13) predicts that sludge plug instability on a gas layer must manifest itself by the formation of surface waves (perturbations) that are less than the diameter D of the storage container; that is,

$$
\lambda_{\text {crit }} \tilde{<} \mathrm{D}
$$

The waves that satisfy the above equation are sufficiently short to ensure the instability of the sludge plug. It is worth mentioning that Epstein (1977) experimentally demonstrated the validity of Eq. (14) for frozen crusts growing on top of columns of less dense, cold liquids in a gravity field.

Combining Eqs. (13) and (14) gives the following criterion for sludge plug instability in terms of sludge yield stress:

$$
\tau \tilde{<} \frac{\rho g D}{12 \pi}
$$

For a deep sludge layer of density $\rho=2 \times 10^{3} \mathrm{~kg} \mathrm{~m}^{-3}$ in a 5 - $\mathrm{ft}$ diameter container $(\mathrm{d}=1.54 \mathrm{~m})$, Eq. (15) indicates an unstable sludge plug for sludge strengths $\tau \tilde{<} 800 \mathrm{~Pa}$. Note that Eq. (15) is identical to the criterion for the initiation of motion of a light sphere of diameter D in a viscoplastic medium with a gravity- yield parameter $\mathrm{Y}_{\mathrm{G}}=(12 \pi)^{-1}=0.027$.

Equation (15) is valid for layered systems with several container-spanning bubbles beneath an equivalent number of inert sludge layers. The only requirement is that the depth $\delta$ of a representative sludge layer is large compared with the wavelength of the disturbance. In mathematical terms this requirement may be expressed as $\exp \left(\mathrm{k}_{\text {crit }} \delta\right) \gg 1.0$ (see, e.g. Epstein, 1977), or

$$
\frac{2 \pi \delta}{\lambda_{\text {crit }}}>2.0
$$


Using Eq. (13) for $\lambda_{\text {crit, }}$ Eq. (16) for the validity of the deep sludge layer approximation may be expressed in the alternative form

$$
\tau \approx \frac{\delta \rho g}{12}
$$

Suppose that the thickness of a representative sludge layer of inert material is $\delta=0.254 \mathrm{~m}$ (10 in). This layer may be regarded as a deep and unstable sludge layer if $\tau \tilde{<415} \mathrm{~Pa}$.

\section{References}

Barnes, J. F., Blewitt, P. J., McQueen, R. G., Meyer, K. A., and Venable, D., 1974, "Taylor Instability in Solids," J. Appl. Physics 4토, pp. 727-732.

Bellman, R. and Pennington, R. H., 1954, "Effects of Surface Tension and Viscosity on Taylor Instability," Quart. J. Appl. Math 12, pp. 151-162.

Blake, A., 1965, Practical Stress Analysis in Engineering Design, Marcel Dekker, Inc., New York.

Epstein, M., 1977, "Stability of a Submerged Frozen Crust," J. Heat Transfer 99, pp. 527-532.

Miles, J. W., 1966, "Taylor Instability of a Flat Plate," General Dynamics, General Atomic Division Report GAMD-7335 (August).

Plys, M. G., 2001, "Particle Settling/Segregation Model," presented at December 20 Sludge Storage Container Meeting, Hanford, WA.

Prager, W. and Hodge, P. G., 1951, Theory of Perfectly Plastic Solids, John Wiley \& Sons, New York.

Taylor, G. I., 1950, "The Instability of Liquid Surfaces When Accelerated in a Direction Perpendicular to Their Planes. I," Proc. Royal Soc. A201, pp. 192-196.

ME:lak 


\section{Distribution}

No. of

\section{Copies}

Offsite

G. L. Dunford

AEM CONSULTING

2417 Mark Avenue

Richland, Washington 99352

2 Fauske and Associates, Inc.

$16 \mathrm{~W} 070$ West $83^{\text {rd }} \mathrm{St}$

Burr Ridge, IL 60521

Attn: M. G. Plys

S. J. Lee

3 Polestar Applied Technology, Inc. 601 Williams Blvd

Suite $2 \mathrm{~A}$

Richland, Washington 99352

Attn: P. Loscoe

E. L. Fuller

E. N. Dodd

J. E. Swenson

Xwest Group, Inc .

1835 Terminal Drive

Richland, Washington 99352

\section{Onsite}

\section{Fluor Hanford}

W. S. Ayers

T3-28

R. B. Baker

A. E. Bridges

W. Coulter

J. F. Cox

B. A. Crea
No. of

\section{Copies}

D. R. Duncan

$\mathrm{X} 4-01$

E. G. Erpenbeck

L0-30

S. L. Hecht

L6-35

J. J. Irwin

L6-35

D. L. McCall

H1-11

L. J. Olguin

H5-24

C. A. Petersen L0-30

J. A. Pottmeyer L0-30

T. J. Ruane X3-61

W.W. Rutherford L0-30

K. Sathyanarayana L6-35

M. J. Schliebe L6-34

J. P. Sloughter X4-01

G. A. Sly X3-85

FHI File/LB (5) L6-35

7 Fluor Federal Services

B. E. Hey (5) X3-79

S. F. Kessler A0-26

M. G. Piepho B4-47

21 Pacific Northwest National Laboratory

S. Q. Bennett K7-90

P. A. Bredt P7-25

P. A. Gauglitz (5) K6-28

W. L. Kuhn K7-15

A. P. Poloski P7-25

A. J. Schmidt K2-12

K. L. Silvers K9-08

G. Terrones (5) K7-15

T. L. Walton K9-45

Information Release (5) K1-06 